\title{
Article \\ The current agri-food dilemma: if the city proposes, does the farmland provide it?
}

\author{
Maria Gemma Grillotti Di Giacomo ${ }^{1}$ and Pierluigi De Felice ${ }^{2, *}$ \\ 1 Faculty of Science and Technology for Human and Environment, Campus Bio-Medico University of Rome, \\ Via Álvaro del Portillo, 21 - 00128 - Roma, Italy; mariagemma.grillotti@gmail.com (M.G.) \\ 2 Humanities Department, University of Salerno; Via Giovanni Paolo II, 132 - 84084 Fisciano (SA), Italy; \\ * Correspondence: pdefelice@unisa.it (P.F.)
}

\begin{abstract}
For decades, the city has created food models by requiring the countryside to meet the growing demand with increasingly more homologated crop reconversions and increasingly vast and competitive farms. The current acceleration of the land concentration process and the dramatic experience of the COVID 19 pandemic have, however, forced us to redefine the city-country relationship, which has been called into question for some years now in various FAO (Food and Agriculture Organization) and EU (European Union) documents. Based on the GECOAGRILANDITALY (Comparative Geography of Agricultural Areas European and non-European) survey itinerary, a proven tool for reading local peculiarities, the authors show how easy it is to recognize which farmlands can best fulfil the role of guaranteeing food safety and protecting the quality and typicality of traditional foods. The final proposal is to start a new agri-food policy that no longer starts from the demand formulated by the city but, reversing the direction of the old relationship, it starts from the availability of products offered by the countryside to re-educate consumption and promote the sustainability of agricultural practices.
\end{abstract}

Keywords: Urban agri-food; GECOAGRI-LANDITALY methodology; European agricultural systems

\section{Introduction}

For thousands of years, the city has generated food models by requiring farmland to satisfy its growing demand, linked to the increase in population concentration, with suitable crop conversion to satisfy it [1].

A relationship - that city-country - that with industrial development has definitively decreed the dominance of the first over the second, both in terms of job offers and services and of productive power and per capita income [2, 3, 4]. Even today, if we only look at Italy, we can see that analysts and data processing centres for the study of nutrition have their official headquarters in urban centres; just think of the location of the FAO and the Word Food Program or the Expo 2015, the time in which the Carta di Milano [5] was approved to reaffirm the universal right to food, or, even more recently, the establishment of local food policies - see City / Region Food Systems at https://www.foode.eu/ [6].

The city has always been the location of political and economic power and a privileged place for diplomatic, commercial and all kinds of information exchanges, it has therefore dictated, and continues to dictate, programs and eating habits and have rarely spoken about the "specialties" of the local products (until the middle of the last century reserved for popular gastronomy) and which, viceversa, were often borrowed from distant cultures and regions (chocolate; sushi, coffee), to underline not only the fascination of exotic foods, as well as the ability to access rare productions and the ease of contamination with the tastes of local traditions [7, 8, 9].

Paradoxically, the city has ended up representing, regardless of its real possibilities of supplying and only by virtue of the possibility of exchanges and connections it offers, the ideal living environment and ensuring the availability of essential goods for survival. A presumed and soon 
cancelled food security, during the most critical historical periods (wars, calamities, epidemics), when rural spaces regain their undisputed function: food supply products and settlement-refuge from the risks associated with demographic concentration. The rediscovery of the countryside in the historical phases of greatest insecurity is a recurring phenomenon, in many cases significantly documented even by literary works - in Boccaccio's Decameron the beauty, healthiness and quality of the countryside food becomes an antidote to the plague $^{1}$ - it is therefore not surprising that the current pandemic COVID 19 has led to the re-evaluation of agricultural spaces for their ability to offer both fresh food, work and hospitality. It is therefore not useless to ask ourselves if, strengthened by the experience lived during the 2020 lockdown and above all, having new communication tools and being able to access services unimaginable only 20-30 years ago, it is possible to redefine and redesign the classic city / countryside relationship. We will try to take this new geographical perspective starting from the tools with which it is possible to know the characteristics of the rural environment in relation to the urban one; an investigation itinerary that will therefore lead us to consider the whole territory as an integrated reality, to be examined as a space organized both by city / countryside and by countryside / city relationship. The exorbitant scientific production (geographic and nongeographical) dedicated to the city-countryside relationship continues unfortunately, still today and unambiguously, to emphasize the dependence of the latter on the demands of the urban population $[11,12,13,14,15,16,17,18,19]$; neither are there any proposals lacking without even speculating whether and how it is possible / appropriate to rebalance this relationship, seek innovative solutions by proposing the transfer of agricultural production from the countryside to the city outskirts (urban gardens cultivated close to built-up areas) or even in central areas high density of downtown housing where crops are attached to the same buildings covered with "vertical gardens" or obtained on artificial soils spread over terraces and roofs [20].

From the experience of the COVID-19 pandemic we are urged to question the deep-rooted urban-centric conception agricultural economy and food. A Conception that today would tend to make the city autarchic/autonomous for its primary needs. Despite the lockdown, the primary sector has never interrupted its multiple productive commercial services. This sector has proven that it is able to continuously ensure easily perishable products with continuity. Farmers were able to innovate promptly, by activating telematic networks and delivering food to homes needed by the urban population in lockdown. In other words, the countryside has shown, how necessary its economic and social function is to the city [21,22].

The same experience of forced isolation, conversely, served to the public to verify, in fact, that it is not only possible, but even advantageous, to work and live far from the city so that, if before the viral invasion of COVID-19 the rural planning of an attractive inhabited space, because organized without being polarized, served without being urbanized and safe without being closed, would perhaps have represented only an interesting exercise in architectural theory. Today the same hypothesis of a different settlement model, valid for every lifestyle and all types of professions, has now entered by right in the debate not only scientific, but also political, ethical and ecological.

Howewer, the new environmental awareness, solicited and fuelled by social movements and political documents of a global scope, has already made us aware that overcoming the exasperated concentration of activities and consumption, distributing them over larger spaces and bringing them closer to the places of production, is not only tantamount to re-establishing a healthier city-country relationship but, even more importantly, to making the relationship between man and the environment more sustainable both from an economic and social point of view. International documents such as the one produced at the Global Forum for Food and Agriculture of 2016, when in Berlin 65 agriculture ministers confirmed the need for accelerated urbanization, to strengthen the "rural-urban" link by promoting sustainable and productive agriculture in order to strengthen and make the agri-food supply chains more efficient to enhance the countryside to make it increasingly

\footnotetext{
${ }^{1}$ Boccaccio sets the Decameron away from the city, besieged by the plague, in the countryside where the beauty and wholesomeness of nature together with the quality of the food -dilicatissimi cibi ed eccellenti vini (Day before) ward off the risks of contagion and disease [10]
} 
attractive and welcoming with the fundamental contribution of women and younger generations [23].

We therefore believe that today it is very important to learn to understand the countryside, not only in relation to the city, but from a systemic territorial perspective, also because in recent decades the land structures of the European countryside are experiencing a process of land concentration which is certainly worrying explicit declaration of the European Parliament (European Parliament resolution of 27 April 2017 on the state of play of farmland concentration in the EU: how to facilitate the access to land for farmers 2016/2141(INI)).

The survey itinerary, proposed here and already tested by the GECOAGRI-LANDITALY Interuniversity Research Group [24,25], uses analysis tools suitable for grasping the multiple potentialities of rural spaces: managed, lost or not yet fully expressed because, as is now said, it allows both to know their peculiarities to enhance them, and to define the various levels of their territorial functionality and then to propose, case by case, if and how it is possible to create a new relationship between the countryside and the city (paragraph 2). In this context, although we are clearly limited to applying the methodology for the sole purpose of knowing the structural characteristics of European agricultural systems, we want to show how it is possible to examine them in their variety and in their temporal evolution (paragraph 3). The analysis will allow us to ascertain in which regions and to what extent the process of land centralisation has transformed rural areas and which countryside can still better meet the needs of cities (paragraph 4).

\section{Method and material}

We intend to dedicate this entire paragraph to the possibility of being familiar with the complexity and potential of agricultural spaces, before seeing how certain analytical tools and the results obtained should be used in applying them to the European Union's countryside.

\subsection{A useful reading rural tool: the GECOAGRI-LANDITALY methodology}

Already presented at the Meeting GIAHS Project of $\mathrm{FAO}^{2}$ in June 2004 and applied to the comparative analysis of agricultural systems in European and non-European countries, the GECOAGRI-LANDITALY survey methodology [26, 27, 28, 29, 30, 31, 32] (filed SIAE 10 January 2007, Repertoire number 2007005663) ${ }^{3}$ has two fundamental characteristics: it is rooted in the concrete reality of the individual regions, because it examines their agricultural spaces starting from the companies that structure the territory by organizing its activities and relationships; it can be applied simultaneously to different geographical scales and repeated to examine the same territory in different historical periods. This flexibility not only allows the comparison of geographically distant and different agricultural realities, by size and economic-social organization but also allows us to grasp the transformations that have taken place in the past and the evolutionary trends in progress to advance useful application proposals. It is not a coincidence that the European Parliament itself in the Resolution of 27 April 2017 stressed the fragmented nature of agricultural reality, complaining that, in the face of a rich availability of information relating to land properties - provided by the farm accountant information network FADN; from the Eurostat survey on the structure of agricultural businesses and from the IACS integrated management and control system - adequate data processing techniques are still lacking to examine the environmental and social aspects of the rural world ${ }^{4}$. On the contrary, the GECOAGRI-LANDITALY methodology takes an integrated, diachronic and transcalar approach (from local to global) and the different parameters used in the research - first of

\footnotetext{
${ }^{2}$ In order to safeguard and support the world's agri-cultural heritage systems, FAO started an initiative for the identification and the dynamic conservation of Globally Important Agricultural Heritage systems (GIAHS) in 2002. These traditional agricultural systems represent models of sustainable agricultural production

${ }^{3}$ The GECOAGRI LANDITALY methodology has been filed with the SIAE (Italian Society of Authors and publishers) to ensure the protection of copyright. The number 2007005663 refers to the document filed.

${ }^{4}$ See P8_TA (2017) 0197 Situation of agricultural concentration in the EU: how to facilitate access for farmers to land European Parliament resolution of 27 April 2017 on the situation regarding agricultural land concentration in the EU: how to facilitate access for farmers to the land (2016/2141 (INI)), p. 3 point O.
} 
all those of the production units with the different weight attributed to: the percentage of the number of farms over the total territory divided according to size classes (Farm quotas, from this moment onwards FQ); the percentage of the total enterprises' land area divided by the different size classes (Farm Area quotas, from this moment onwards FA) over the total territory under investigation; the percentage of the weighed enterprises' Cultivated Agricultural Area (from this moment onwards CAA) ${ }^{5}$ and Utilised Agricultural Area (from this moment onwards UAA) - help to interpret the complexity and originality of the rural world and, ultimately, to propose targeted and sustainable interventions for a contemporary society.

The research is developed through successive stages: empirical-descriptive; experimental interpretative and evaluative-application; phases that, although distinct as each provides for the processing of different data and parameters, are consequential and complementary; the progression in fact moves from the knowledge of the complex rural reality up to the formulation of application interventions. With the first empirical-descriptive phase we get to know the external characteristics (environmental, technological, political) and the structural characteristics of the territory being studied; aspects that allow us to know: which companies in fact govern the primary sector of that territory; how agricultural activity and production are organized and what evolutionary pressures have transformed or tend to transform it over time.

The experimental-interpretative phase examines the economic and social characteristics of the area under study; appropriate elaboration of data relating to: the cultivation and breeding choices adopted by the businesses; the gross saleable production of crops and livestock; the destination of the products and the type of commercial networks, lead us to measure the density and intensity of production of the cultivated areas; to calculate the economic weight of the different types of businesses; to identify the cultivation and / or multifunctional systems that have been adopted over time, while the title of ownership of the land, together with the commitment required - in terms of annual working days - by the different types of production systems and the demographic structure of the farmers help us outline the social reality of the area examined area.

The complex of economic and social characteristics revealed that in some cases we are faced with rich farmland with poor farmers (high crop intensity and high operating costs), while in other cases we observe poor farmland with rich farmers (low-cost crop choices exercise and low crop intensity). What is more important is that from this second phase of investigation it is finally possible to establish the different levels of sectoral and territorial functionality that characterize rural spaces by modelling the same forms of the landscape.

The last phase of the GECOAGRI-LANDITALY methodological itinerary was defined as evaluative and propositional / applicative because with the examination of territorial characteristics (forms of settlement and types of dwellings; levels of services and communication networks; tourist attraction capacity) and cultural characteristics (quality and typicality of local productions; food traditions; heritage and historical-cultural events) allows to evaluate the development potential of each rural area. Once its strengths and weaknesses have been identified, it will in fact be possible to examine the evolutionary trends in progress, as well as the opportunities and risks of any interventions to be carried out on the territory under review.

This apparently complex research path can be applied both ex post (using data from surveys conducted in past decades) and ex ante (projecting the observed variations to future decades), to prefigure how the organization will change and the local development of an agricultural region.

\subsection{Materials, elements and parameters to be used to be familiar with agricultural space}

\footnotetext{
${ }^{5}$ CAA is a key indicator of the economic and operational commitment of farm holders. In fact, it includes only the land actually cultivated by farmers, that is, ploughed, sown and irrigated and fertilized as needed. The UAA includes permanent non cultivated grassland from which forage and biomass are obtained, used but not cultivated. It should be noted that the Eurostat data in the definition of permanent grassland do not clearly specify the significant difference between cultivated permanent grassland and cultivated permanent grassland, therefore, in our calculations we preferred to completely exclude this item from the CAA.
} 
Privileged sources for the knowledge of the agricultural world are certainly the official data of census surveys and those obtained from surveys and monitoring, commissioned for various reasons by national and international bodies ${ }^{6}$; this is valuable information which, however, must always be accompanied by others of a general nature and, above all, by those obtained with direct inspections on the territory and with interviews with local operators.

For convenience and space saving, we consider it appropriate to outline in six thematic areas that our methodology defines "characters"7 the set of material useful to interpret the rural world:

- external characteristics: natural environments, agricultural policies and technological innovations; they cover a wide range of factors which, regardless of the will and / or action of the farmer, manage to influence both agronomic choices and the results of agricultural work and can be grouped into three broad sectors ranging from climatic-morphological environmental aspects to the local, national and international agricultural policies, up to the development of agronomic techniques, which are now increasingly sophisticated, with respect to which the farmer can exercise as a stimulus, without influencing the results;

- the structural characteristics: type and number of agricultural enterprises, surface width (FA) and cultivated area (CAA); they are the fundamental elements of every agricultural reality; without knowing them any reflection risks losing concreteness and meaning. The farm is in fact the absolute protagonist of the unique relationship that unites a human community (rural and urban) with the natural environment in which it lives. The examination of the different combinations and relationships between these elements allows us to outline the dominant agricultural system in the examined region (see Table 1) and the eloquent representation of this relationship is given by the "graph of the agricultural system". A tool built and also used to develop intervention policies at different geographical scales (see paragraph 3).

- economic characteristics: crop and production arrangements, gross saleable production (GSP) of crops and livestock ${ }^{8}$, type of supply chain and product marketing times (daily, weekly, seasonal; local, regional, national, global), possibilities and ease of access to agri-food production; with these indicators it is possible to distinguish density (CAA/FA) ${ }^{9}$ and intensity of agricultural practices (GSP $x$ ha of CAA) ${ }^{10}$; interpret the different territorial impact and measure the economic weight of the different types of production units operating in the examined region (see Table 2 and Table 3).

Table 1. Structural character processing table. In the table, the rows are marked with letters of the alphabet and the columns with cardinal numbers. $\mathrm{N}=$ Census data. $\mathrm{X}$ =meadow pastures + woods-poplar woods (with $\mathrm{i}=\mathrm{a}, \mathrm{b}, \mathrm{c}, \mathrm{d}, \mathrm{e}, \mathrm{f}$ ).

\footnotetext{
${ }^{6}$ Among the most accredited sources we mention FAOSTAT, EUROSTAT, Land Matrix

7 Detailed information on the indicators to be developed to examine the different characters can be found in $[24,25]$.

8 The calculation of the GSP of crops and / or livestock represents a real leap in quality in the itinerary of investigations on local agricultural systems because it allows:

. to identify from which types of agricultural practices the income produced derives and which types of farms actually produce in the primary sector of the territory considered;

- to establish the economic weight of companies regardless of their surface size;

- to calculate the average productivity of production units operating in different areas and / or belonging to classes of different size;

- to measure the intensity of production practices;

- to evaluate the evolutionary trends of primary activity (some spy crops signal processes of intensification and others of rarefaction of agricultural practices) and the incidence of crops and livestock on the income of the primary sector;

${ }_{9}$ Crop density (DC) is the ratio of the total farm area (FA) and the area actually cultivated (CAA) in the considered territory; expressed by the formula DC = CAAx100 / FA

10 The crop intensity (IC) is, on the other hand, the revenue, that is the GSP, per hectare of CAA cultivated area in the considered territory; expressed by the formula IC = GSP $x$ ha of CAA
} 


\begin{tabular}{|c|c|c|c|c|c|c|c|c|}
\hline $\begin{array}{c}\text { Classes } \\
\text { of size } \\
\text { (ha) }\end{array}$ & & $\begin{array}{c}\text { Farms } \\
\text { (no.) } \\
(1)\end{array}$ & $\begin{array}{c}\text { Farms area } \\
\text { (hectares) } \\
\text { (2) }\end{array}$ & $\begin{array}{c}\text { Farm } \% \\
\text { (3) }\end{array}$ & $\begin{array}{c}\text { Farm } \\
\text { areas } \% \\
\text { against } \\
\text { total for } \\
\text { territory } \\
\quad(4)\end{array}$ & $\begin{array}{c}\text { Cultiveted } \\
\text { Agricultural } \\
\text { Areas } \\
\text { (CAA) } \\
\text { no. } \\
\text { ha } \\
\text { (5) }\end{array}$ & $\begin{array}{c}\text { Cultivated } \\
\text { Agricultural } \\
\text { Areas CAA } \\
\text { \% against } \\
\text { total Farm } \\
\text { area } \\
\text { (adjusted) } \\
\text { (6) }\end{array}$ & $\begin{array}{c}\text { CAA } \\
\text { Average } \\
\text { farm } \\
\text { area } \\
(7)\end{array}$ \\
\hline $0-2$ & (a) & $\mathrm{N}$ & $\mathrm{N}$ & $\frac{a 1}{f 1} \times 100$ & $\frac{a 2}{f 2} \times 100$ & $\mathrm{a} 2-\mathrm{X}_{\mathrm{a}}$ & $\frac{a 5}{f 2} \times 100$ & $\frac{a 2}{a 1}$ \\
\hline $2-5$ & (b) & $\mathrm{N}$ & $\mathrm{N}$ & $\frac{b 1}{f 1} x 100$ & $\frac{b 2}{f 2} \times 100$ & b2-X & $\frac{b 5}{f 2} \times 100$ & $\frac{b 2}{b 1}$ \\
\hline $5-20$ & (c) & $\mathrm{N}$ & $\mathrm{N}$ & $\frac{c 1}{f 1} \times 100$ & $\frac{c 2}{f 1} x 100$ & c2-X & $\frac{c 5}{f 2} \times 100$ & $\frac{c 2}{c 1}$ \\
\hline $20-50$ & (d) & $\mathrm{N}$ & $\mathrm{N}$ & $\frac{d 1}{f 1} x 100$ & $\frac{d 2}{f 1} x 100$ & $d 2-X$ & $\frac{d 5}{f 2} x 100$ & $\frac{d 2}{d 1}$ \\
\hline$>50$ & (e) & $\mathrm{N}$ & $\mathrm{N}$ & $\frac{e 1}{f 1} x 100$ & $\frac{e 2}{f 1} x 100$ & e2-X & $\frac{e 5}{f 2} \times 100$ & $\frac{e 2}{e 1}$ \\
\hline Total & (f) & $\mathrm{a} 1+\mathrm{b} 1+\mathrm{c} 1+\mathrm{d} 1+\mathrm{e} 1$ & $\mathrm{a} 2+\mathrm{b} 2+\mathrm{c} 2+\mathrm{d} 2+\mathrm{e} 2$ & 100 & 100 & $\mathrm{f} 2-\mathrm{X}$ & $\frac{f 5}{f 2} \times 100$ & $\frac{f 2}{f 1}$ \\
\hline
\end{tabular}

Table 2. A and B Production and cultivation systems of agricultural farms in the examined area. In each element of the formulas, the index refers to other tables for the elaboration of which is seen [24, 25].

\begin{tabular}{|c|c|c|c|c|c|c|c|}
\hline Class size & & $\begin{array}{c}\text { \% GSP livestock } \\
\text { Of total GSP } \\
\text { (11) }\end{array}$ & $\begin{array}{c}\text { \% GSP } \\
\text { cattle } \\
(12)\end{array}$ & $\begin{array}{l}\text { \% GSP } \\
\text { equine } \\
\text { (13) }\end{array}$ & $\begin{array}{c}\text { \% GSP } \\
\text { swine } \\
\text { (14) }\end{array}$ & $\begin{array}{l}\text { \% GSP } \\
\text { ovine } \\
\text { caprine } \\
(15)\end{array}$ & $\begin{array}{c}\% \text { GSP } \\
\text { poultry } \\
(16)\end{array}$ \\
\hline $0-2$ (ha) & (a) & $\frac{(a 6) T \delta}{(f 1) T 4} \times 100$ & $\frac{(a 1) T \delta}{(f 1) T 4} \times 100$ & $\frac{(a 2) T \delta}{(f 1) T 4} \times 100$ & $\frac{(a 3) T \delta}{(f 1) T 4} \times 100$ & $\frac{(a 4) T \delta}{(f 1) T 4} \times 100$ & $\frac{(a 5) T \delta}{(f 1) T 4} \times 100$ \\
\hline 2-5 (ha) & (b) & $\frac{(b 6) T \delta}{(f 1) T 4} \times 100$ & $\frac{(b 1) T \delta}{(f 1) T 4} x 100$ & $\frac{(b 2) T \delta}{(f 1) T 4} \times 100$ & $\frac{(b 3) T \delta}{(f 1) T 4} \times 100$ & $\frac{(b 4) T \delta}{(f 1) T 4} \times 100$ & $\frac{(b 5) T \delta}{(f 1) T 4} \times 100$ \\
\hline 5-20 (ha) & (c) & $\frac{(c 6) T \delta}{(f 1) T 4} \times 100$ & $\frac{(c 1) T \delta}{(f 1) T 4} \times 100$ & $\frac{(c 2) T \delta}{(f 1) T 4} \times 100$ & $\frac{(c 3) T \delta}{(f 1) T 4} \times 100$ & $\frac{(c 4) T \delta}{(f 1) T 4} \times 100$ & $\frac{(c 5) T \delta}{(f 1) T 4} \times 100$ \\
\hline 20-50 (ha) & (d) & $\frac{(d 6) T \delta}{(f 1) T 4} \times 100$ & $\frac{(d 1) T \delta}{(f 1) T 4} \times 100$ & $\frac{(d 2) T \delta}{(f 1) T 4} \times 100$ & $\frac{(d 3) T \delta}{(f 1) T 4} \times 100$ & $\frac{(d 4) T \delta}{(f 1) T 4} \times 100$ & $\frac{(d 5) T \delta}{(f 1) T 4} \times 100$ \\
\hline$>50$ (ha) & (e) & $\frac{(e 6) T \delta}{(f 1) T 4} \times 100$ & $\frac{(e 1) T \delta}{(f 1) T 4} \times 100$ & $\frac{(e 2) T \delta}{(f 1) T 4} \times 100$ & $\frac{(e 3) T \delta}{(f 1) T 4} \times 100$ & $\frac{(e 4) T \delta}{(f 1) T 4} \times 100$ & $\frac{(e 5) T \delta}{(f 1) T 4} \times 100$ \\
\hline Total & (f) & $\frac{(f 6) T \delta}{(f 1) T 4} \times 100$ & $\frac{(f 1) T \delta}{(f 1) T 4} \times 100$ & $\frac{(f 2) T \delta}{(f 1) T 4} \times 100$ & $\frac{(f 3) T \delta}{(f 1) T 4} \times 100$ & $\frac{(f 4) T \delta}{(f 1) T 4} \times 100$ & $\frac{(f 5) T \delta}{(f 1) T 4} \times 100$ \\
\hline
\end{tabular}




\begin{tabular}{|c|c|c|c|c|c|c|c|c|c|c|c|}
\hline Class size & & $\begin{array}{l}\text { \% GSP crops } \\
\text { of totale } \\
\text { GSP } \\
\text { (1) }\end{array}$ & $\begin{array}{c}\% \text { GSP } \\
\text { cereal } \\
(2)\end{array}$ & $\begin{array}{c}\text { \% GSP } \\
\text { Vegetabl } \\
\text { es } \\
(3)\end{array}$ & $\begin{array}{c}\text { \% GSP } \\
\text { Industrial } \\
\text { cultivations } \\
\text { (4) }\end{array}$ & $\begin{array}{c}\% \text { GSP } \\
\text { forage } \\
(5)\end{array}$ & $\begin{array}{c}\text { \% GSP } \\
\text { vineyard } \\
\mathrm{s} \\
(6)\end{array}$ & $\begin{array}{c}\text { \% GSP } \\
\text { olives } \\
(7)\end{array}$ & $\begin{array}{c}\% \text { GSP } \\
\text { Fruit } \\
(8)\end{array}$ & $\begin{array}{c}\text { \% GSP } \\
\text { Vineyard } \\
\mathrm{s} \\
(9)\end{array}$ & $\begin{array}{c}\% \text { GSP } \\
\text { forests } \\
10\end{array}$ \\
\hline $0-2$ (ha) & (a) & $\frac{(a 10) T 8}{(f 1) T 4} \times 100$ & $\frac{(a 1) T 8}{(f 1) T 4} \times 10$ & $\frac{(a 2) T 8}{(f 1) T 4} \times 10($ & $\frac{(a 3) T 8}{(f 1) T 4} \times 100$ & $\frac{(a 4) T 8}{(f 1) T 4} \times 10$ & $\frac{(a 5) T 8}{(f 1) T 4} \times 10$ & $\frac{(a 6) T 8}{(f 1) T 4} \times 10$ & $\frac{(a 7) T 8}{(f 1) T 4} \times 10$ & $\frac{(a 8) T 8}{(f 1) T 4} \times 10$ & $\frac{(a 9) T 8}{(f 1) T 4} \times 10$ \\
\hline 2-5 (ha) & (b) & $\frac{(b 10) T 8}{(f 1) T 4} \times 100$ & $\frac{(b 1) T 8}{(f 1) T 4} \times 10$ & $\frac{(b 2) T 8}{(f 1) T 4} \times 10($ & $\frac{(b 3) T 8}{(f 1) T 4} \times 100$ & $\frac{(b 4) T 8}{(f 1) T 4} \times 10$ & $\frac{(b 5) T 8}{(f 1) T 4} \times 10$ & $\frac{(b 6) T 8}{(f 1) T 4} \times 10$ & $\frac{(b 7) T 8}{(f 1) T 4} \times 10$ & $\frac{(b 8) T 8}{(f 1) T 4} \times 10$ & $\frac{(b 9) T 8}{(f 1) T 4} \times 10$ \\
\hline 5-20 (ha) & (c) & $\frac{(c 10) T 8}{(f 1) T 4} \times 100$ & $\frac{(c 1) T 8}{(f 1) T 4} \times 10$ & $\frac{(c 2) T 8}{(f 1) T 4} \times 10($ & $\frac{(c 3) T 8}{(f 1) T 4} \times 100$ & $\frac{(c 4) T 8}{(f 1) T 4} \times 10$ & $\frac{(c 5) T 8}{(f 1) T 4} \times 10$ & $\frac{(c 6) T 8}{(f 1) T 4} \times 10$ & $\frac{(c 7) T 8}{(f 1) T 4} \times 10$ & $\frac{(c 8) T 8}{(f 1) T 4} \times 10$ & $\frac{(c 9) T 8}{(f 1) T 4} \times 10$ \\
\hline 20-50 (ha) & (d) & $\frac{(d 10) T 8}{(f 1) T 4} \times 100$ & $\frac{(d 1) T 8}{(f 1) T 4} \times 10$ & $\frac{(d 2) T 8}{(f 1) T 4} \times 10($ & $\frac{(d 3) T 8}{(f 1) T 4} \times 100$ & $\frac{(d 4) T 8}{(f 1) T 4} \times 10$ & $\frac{(d 5) T 8}{(f 1) T 4} \times 10$ & $\frac{(d 6) T 8}{(f 1) T 4} \times 10$ & $\frac{(d 7) T 8}{(f 1) T 4} \times 10$ & $\frac{(d 8) T 8}{(f 1) T 4} \times 10$ & $\frac{(d 9) T 8}{(f 1) T 4} \times 10$ \\
\hline$>50$ (ha) & (e) & $\frac{(e 10) T 8}{(f 1) T 4} \times 100$ & $\frac{(e 1) T 8}{(f 1) T 4} \times 10$ & $\frac{(e 2) T 8}{(f 1) T 4} \times 10($ & $\frac{(e 3) T 8}{(f 1) T 4} \times 100$ & $\frac{(e 4) T 8}{(f 1) T 4} \times 10$ & $\frac{(e 5) T 8}{(f 1) T 4} \times 10$ & $\frac{(e 6) T 8}{(f 1) T 4} \times 10$ & $\frac{(e 7) T 8}{(f 1) T 4} \times 10$ & $\frac{(e 8) T 8}{(f 1) T 4} \times 10$ & $\frac{(e 9) T 8}{(f 1) T 4} \times 10$ \\
\hline Total & (f) & $\frac{(f 10) T 8}{(f 1) T 4} \times 100$ & $\frac{(f 1) T 8}{(f 1) T 4} \times 10$ & $\frac{(f 2) T 8}{(f 1) T 4} \times 10($ & $\frac{(f 3) T 8}{(f 1) T 4} \times 100$ & $\frac{(f 4) T 8}{(f 1) T 4} \times 10$ & $\frac{(f 5) T 8}{(f 1) T 4} \times 10$ & $\frac{(f 6) T 8}{(f 1) T 4} \times 10$ & $\frac{(f 7) T 8}{(f 1) T 4} \times 10$ & $\frac{(f 8) T 8}{(f 1) T 4} \times 10$ & $\frac{(f 9) T 8}{(f 1) T 4} \times 10$ \\
\hline
\end{tabular}


Table 3. Economic weight of the agricultural farms of the territory considered. In each element of the formulas, the index refers to other tables for the elaboration of which is seen [24, 25].

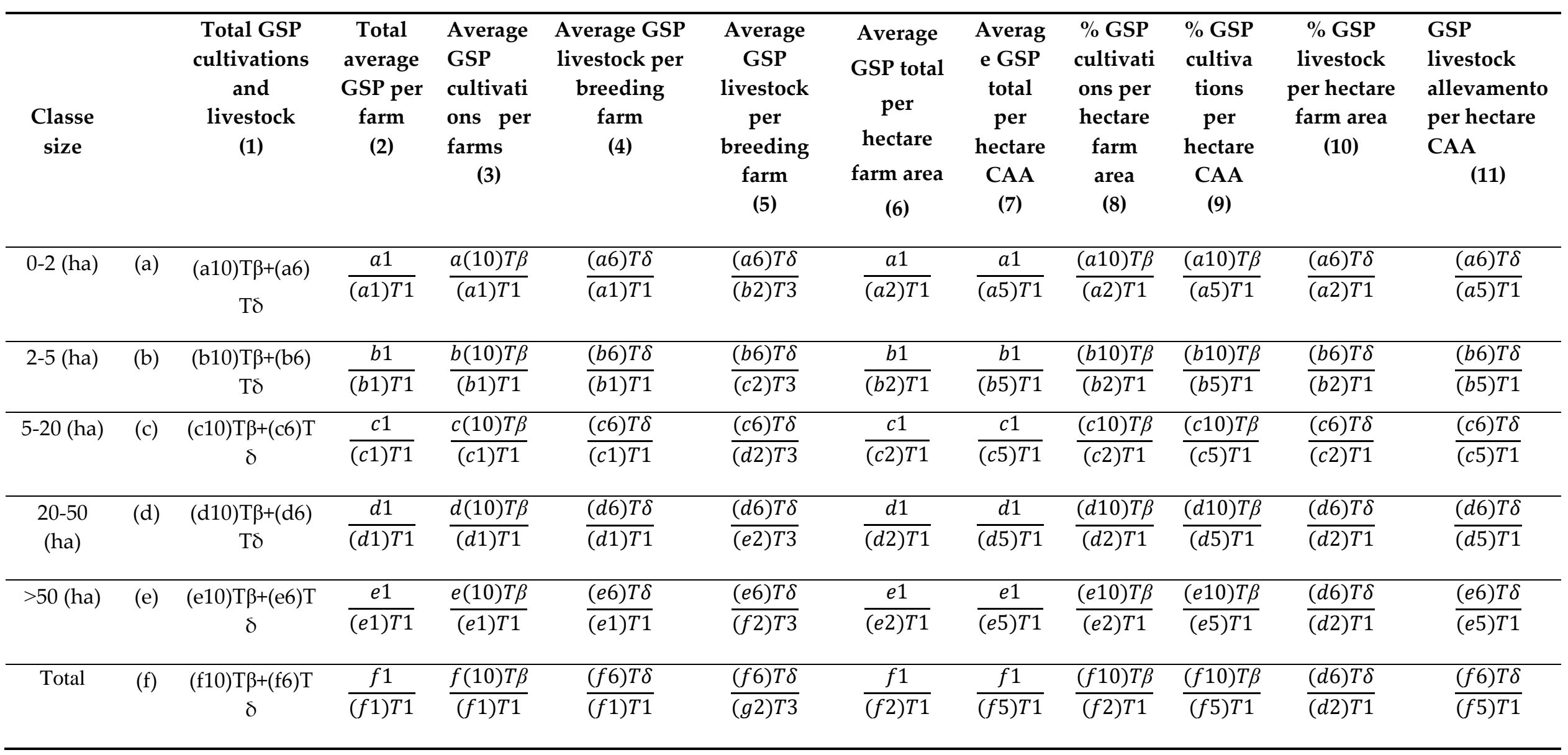


- social characteristics: demographic structure of farmers and of the workforce (see graph. $1^{11}$ ), title of ownership of the land, agricultural year ${ }^{12}$ (see Fig. 1) and number of average working days per hectare of CAA, , levels of services used by businesses and present in rural dwellings; the set of these parameters gives a clear idea of the socio-economic conditions in which the rural population of the examined area lives and at the same time defines the attractiveness that it can exercise both in terms of seasonal tourism and the permanent transfer of urban residences (see Tab. $4)$.

- the territorial characteristics: variety of rural settlements (centralized, annexed, scattered), arrangement of soils and forms of fields, cultivation and breeding techniques, presence of infrastructures and commercial and social-health services; to this end, which is closely linked to the beauty of rural landscapes and the very possibility of developing multifunctional non-agricultural activities, from tourism to social activities, we must define and distinguish the sectoral functionality and territorial functionality of a rural space while. While the former can be measured through the profitability and competitiveness of the primary sector, the latter can only be assessed by examining the vitality of the settlement, the territorial organization and the services offered to the population that resides there (see Tab. 5).

- cultural characteristics: cultural traditions and biodiversity, specialties and quality of agrifood products, toponyms, sacred ceremonies and rural holidays, local markets and traditional festivals, farmer rites and songs; agricultural operations have communicated with the life of human communities, generating millenary cultural and food traditions; culture and crops therefore enter into a two-way relationship to be rediscovered and valued everywhere, just as some important projects activated on a global scale (UNESCO sites; GHIAS) teach us to do. The extraordinary richness of the rural world and the schematic nature with which we wanted to indicate the way to go in order to try to know it through its different characteristics, should not discourage at all, rather they should rather stimulate those who want to devote themselves to the study of the primary sector, agri-food and of the urban-rural relationship; the latter, in fact, is still waiting to be understood in all its functions, not only economic, but also and above all social, aesthetic and ethical.

\footnotetext{
${ }^{11}$ The demographic structure of the agricultural lessees of the examined territory, if compared with that of the lessees of the only companies that characterize the agricultural system of the same territory, allows to evaluate the consistency of agricultural under-employment in the less representative production units of the system.

12 The construction of the graph of the agricultural year records the different phases of work from the preparation and arrangement of the fields, to the care of crops and livestock in the various stages of growth, up to the harvest of the finished product.
} 


\section{Piemonte}
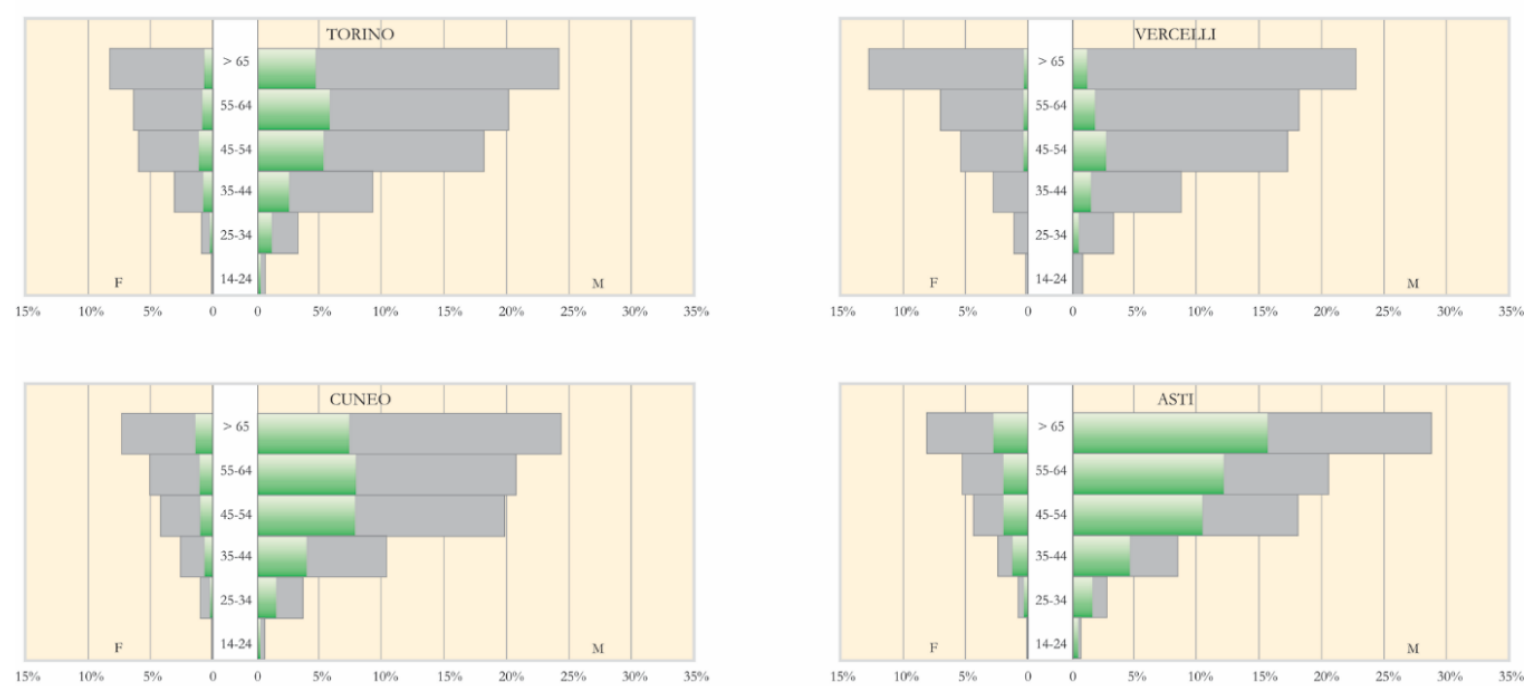

age pyramid for farm owners in provinces

age pyramid for owners of farms that predominate in provincial agricultural system

Graphic 1. Age pyramids of agricultural lessees of some Italian provincial territories characterized by different agricultural systems. In grey the age pyramids of the agricultural lessees of the provinces. In green, the age pyramids of only the owners of the farms that characterize the provincial agricultural system. Source $[24,25]$.

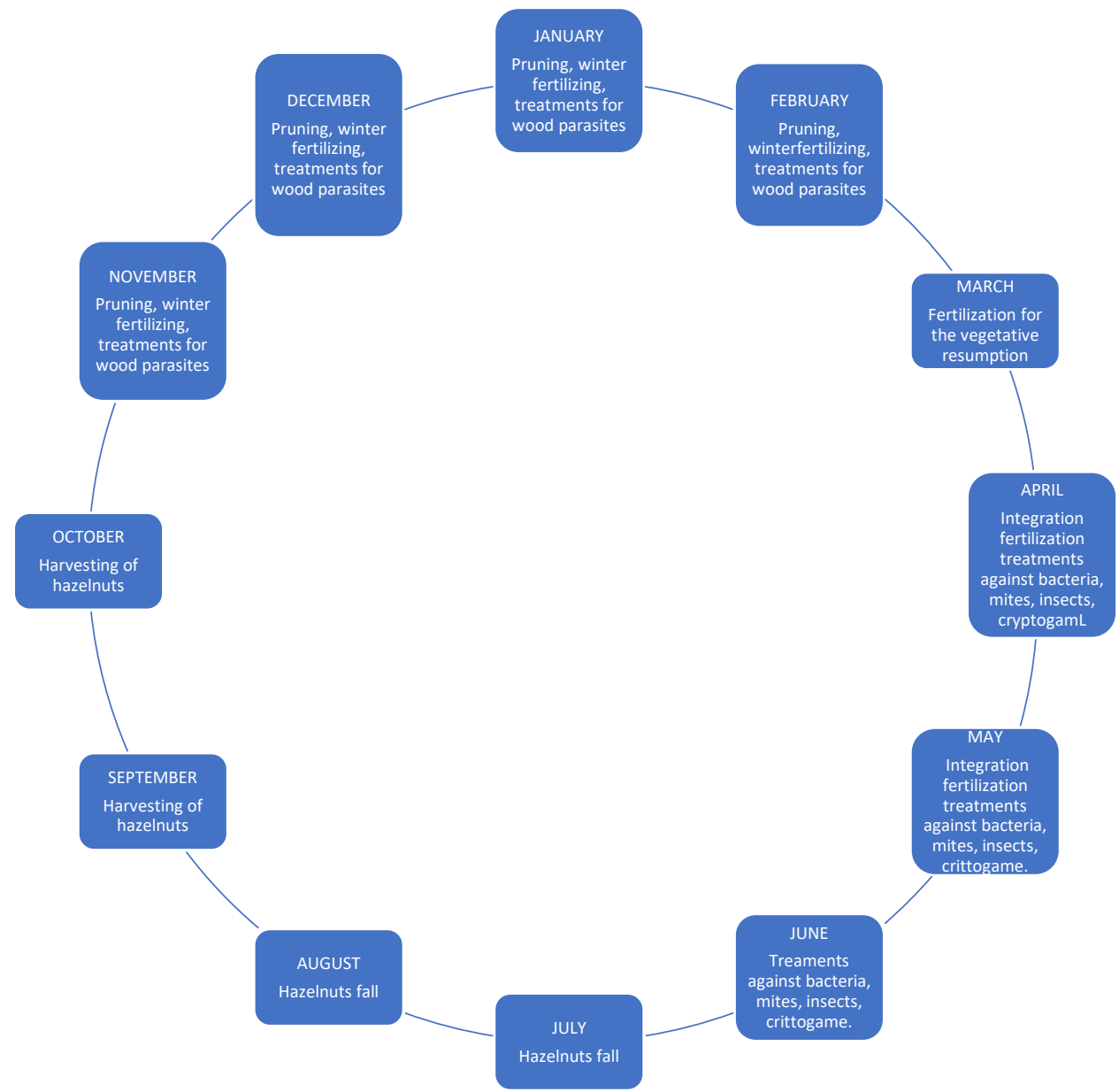

Figure 1. Agricultural year relating to holi growing in the countryside of Viterbo Italy. Source: [24,25]. 
Table 4. Economic and social characteristics of agriculture in the territory being considered.

\begin{tabular}{|c|c|c|c|c|c|c|c|c|c|}
\hline \multirow[t]{8}{*}{1} & \multicolumn{9}{|c|}{ Table 4. Economic and social characteristics of agriculture in the territory being considered. } \\
\hline & $\begin{array}{c}\text { Classes } \\
\text { of size } \\
\text { (ha) }\end{array}$ & & $\begin{array}{c}\text { Crop } \\
\text { densit } \\
y \\
(1)\end{array}$ & $\begin{array}{c}\text { Crop } \\
\text { intensit } \\
y \\
(2)\end{array}$ & $\begin{array}{c}\text { GSP } \\
\text { Crop } \\
\text { incidence } \\
\text { of tot. } \\
\text { GSP } \\
\text { (3) }\end{array}$ & $\begin{array}{c}\text { N. of } \\
\text { working } \\
\text { days } \\
\text { (4) }\end{array}$ & $\begin{array}{c}\text { N. of } \\
\text { working } \\
\text { days per } \\
\text { hectare of } \\
\text { farm area } \\
\text { (5) }\end{array}$ & $\begin{array}{c}\mathrm{N} . \\
\text { working } \\
\text { days per } \\
\text { ha of } \\
\text { CAA } \\
\text { (6) }\end{array}$ & $\begin{array}{l}\text { Average } \\
\text { total GSP } \\
\text { per } \\
\text { working } \\
\text { day }\end{array}$ \\
\hline & $0-2$ & (a) & (a6)T1 & (a9)T4 & (a1)T5 & $\mathrm{N}$ & $\frac{a 4}{(a 2) T 1}$ & $\frac{a 4}{(a 5) T 1}$ & $\frac{(a 1) T 4}{a 4}$ \\
\hline & $2-5$ & (b) & (b6)T1 & (b9)T4 & (b1)T5 & $\mathrm{N}$ & $\frac{b 4}{(b 2) T 1}$ & $\frac{b 4}{(a b 5) T 1}$ & $\frac{(b 1) T 4}{b 4}$ \\
\hline & $5-20$ & (c) & (c6)T1 & $(\mathrm{c} 9) \mathrm{T} 4$ & (c1)T5 & $\mathrm{N}$ & $\frac{c 4}{(c 2) T 1}$ & $\frac{c 4}{(c 5) T 1}$ & $\frac{(c 1) T 4}{c 4}$ \\
\hline & $20-50$ & (d) & $(\mathrm{d} 6) \mathrm{T} 1$ & $(\mathrm{~d} 9) \mathrm{T} 4$ & $(\mathrm{~d} 1) \mathrm{T} 5$ & $\mathrm{~N}$ & $\frac{d 4}{(d 2) T 1}$ & $\frac{d 4}{(d 5) T 1}$ & $\frac{(d 1) T 4}{d 4}$ \\
\hline & $>50$ & (e) & (e6)T1 & $(\mathrm{e} 9) \mathrm{T} 4$ & (e1)T5 & $\mathrm{N}$ & $\frac{e 4}{(e 2) T 1}$ & $\frac{e 4}{(e 5) T 1}$ & $\frac{(e 1) T 4}{e 4}$ \\
\hline & Total & (f) & $(\mathrm{f} 6) \mathrm{T} 1$ & $\begin{array}{l}(\mathrm{f} 9) \mathrm{T} 4 \\
\end{array}$ & $\begin{array}{l}\text { (f1)T5 } \\
\text {. }\end{array}$ & $\mathrm{N}$ & $\frac{f 4}{(f 2) T 1}$ & $\frac{f 4}{(a f 5) T 1}$ & $\frac{(f 1) T 4}{f 4}$ \\
\hline
\end{tabular}




Table 5. Spread of agricultural and non-agricultural part-time work in the territory of the farms being analysed.

\begin{tabular}{|c|c|c|c|c|c|c|c|c|c|c|c|c|c|c|c|c|c|}
\hline \multirow[t]{2}{*}{$\begin{array}{l}\text { Class } \\
\text { size }\end{array}$} & & \multirow[t]{2}{*}{$\begin{array}{l}\text { Full } \\
\text { Time } \\
\text { (1) }\end{array}$} & \multirow[t]{2}{*}{$\begin{array}{l}\% \text { of total } \\
\text { farms } \\
\text { (2) }\end{array}$} & \multirow[t]{2}{*}{$\begin{array}{c}\text { Part } \\
\text { time } \\
(3)\end{array}$} & \multirow[t]{2}{*}{$\begin{array}{l}\% \text { of total } \\
\text { farms } \\
\text { (4) }\end{array}$} & \multirow{2}{*}{$\begin{array}{c}\text { Part- } \\
\text { time } \\
\text { farming } \\
(5)\end{array}$} & \multirow{2}{*}{$\begin{array}{c}\% \text { of total } \\
\text { farms } \\
\text { (6) }\end{array}$} & \multirow{2}{*}{$\begin{array}{c}\text { Part- } \\
\text { time } \\
\text { extra } \\
\text { farmi } \\
\text { ng } \\
\text { (7) }\end{array}$} & \multirow{2}{*}{$\begin{array}{c}\% \text { of total } \\
\text { farms } \\
\text { (8) }\end{array}$} & \multirow{2}{*}{$\begin{array}{c}\text { Part- } \\
\text { time } \\
\text { industry } \\
(9)\end{array}$} & \multirow[t]{2}{*}{$\begin{array}{l}\text { \% of total } \\
\text { farms } \\
\text { (10) }\end{array}$} & \multirow[t]{2}{*}{$\begin{array}{l}\text { Part-time } \\
\text { commercial } \\
\text { (11) }\end{array}$} & \multirow{2}{*}{$\begin{array}{c}\% \text { of total } \\
\text { farms } \\
\text { (12) }\end{array}$} & \multirow{2}{*}{$\begin{array}{c}\text { Part- } \\
\text { time } \\
\text { other } \\
\text { sector } \\
\mathrm{s} \\
\text { (13) }\end{array}$} & \multirow[t]{2}{*}{$\begin{array}{l}\text { \% of total } \\
\text { farms } \\
\text { (14) }\end{array}$} & \multicolumn{2}{|c|}{$\begin{array}{c}\text { Part-time paid } \\
\text { activity mainly at } \\
\text { the farms }\end{array}$} \\
\hline & & & & & & & & & & & & & & & & $\begin{array}{c}N \\
(15)\end{array}$ & $\begin{array}{l}\% \\
(16)\end{array}$ \\
\hline $0-2$ (ha) & (a) & $\mathrm{N}$ & $\frac{a 1}{(a 1) T 1} \times 100$ & $\mathrm{~N}$ & $\frac{(a 3)}{(a 1) T 1} X 100$ & $\mathrm{~N}$ & $\frac{(a 5)}{(a 1) T 1} X 100$ & $\mathrm{~N}$ & $\frac{(a 7)}{(a 1) T 1} \times 100$ & $\mathrm{~N}$ & $\frac{(a 9)}{(a 1) T 1} X 100$ & $\mathrm{~N}$ & $\frac{(a 11)}{(a 1) T 1} X 100$ & $\mathrm{~N}$ & $\frac{(a 11)}{(a 1) T 1} X 100$ & $\mathrm{~N}$ & $\frac{(a 15)}{(a 1) T 1} \times 100$ \\
\hline $2-5$ (ha) & (b) & $\mathrm{N}$ & $\frac{b 1}{(b 1) T 1} \times 100$ & $\mathrm{~N}$ & $\frac{(b 3)}{(b 1) T 1} X 100$ & $\mathrm{~N}$ & $\frac{(b 5)}{(b 1) T 1} X 100$ & $\mathrm{~N}$ & $\frac{(b 7)}{(b 1) T 1} X 100$ & $\mathrm{~N}$ & $\frac{(b 9)}{(b 1) T 1} X 100$ & $\mathrm{~N}$ & $\frac{(b 11)}{(b 1) T 1} X 100$ & $\mathrm{~N}$ & $\frac{(b 11)}{(b 1) T 1} \times 100$ & $\mathrm{~N}$ & $\frac{(b 15)}{(b 1) T 1} \times 100$ \\
\hline 5-20 (ha) & (c) & $\mathrm{N}$ & $\frac{c 1}{(c 1) T 1} \times 100$ & $\mathrm{~N}$ & $\frac{(c 3)}{(c 1) T 1} \times 100$ & $\mathrm{~N}$ & $\frac{(c 5)}{(c 1) T 1} \times 100$ & $\mathrm{~N}$ & $\frac{(c 7)}{(c 1) T 1} \times 100$ & $\mathrm{~N}$ & $\frac{(c 9)}{(c 1) T 1} \times 100$ & $\mathrm{~N}$ & $\frac{(c 11)}{(c 1) T 1} \times 100$ & $\mathrm{~N}$ & $\frac{(c 11)}{(c 1) T 1} X 100$ & $\mathrm{~N}$ & $\frac{(a c 15)}{(c 1) T 1} \times 100$ \\
\hline 20-50 (ha) & (d) & $\mathrm{N}$ & $\frac{d 1}{(d 1) T 1} \times 100$ & $\mathrm{~N}$ & $\frac{(d 3)}{(d 1) T 1} \times 100$ & $\mathrm{~N}$ & $\frac{(d 5)}{(d 1) T 1} X 100$ & $\mathrm{~N}$ & $\frac{(d 7)}{(d 1) T 1} X 100$ & $\mathrm{~N}$ & $\frac{(d 9)}{(d 1) T 1} \times 100$ & $\mathrm{~N}$ & $\frac{(d 11)}{(d 1) T 1} \times 100$ & $\mathrm{~N}$ & $\frac{(d 11)}{(d 1) T 1} \times 100$ & $\mathrm{~N}$ & $\frac{(d 15)}{(d 1) T 1} \times 100$ \\
\hline$>50$ (ha) & (e) & $\mathrm{N}$ & $\frac{e 1}{(e 1) T 1} X 100$ & $\mathrm{~N}$ & $\frac{(e 3)}{(e 1) T 1} \times 100$ & $\mathrm{~N}$ & $\frac{(e 5)}{(e 1) T 1} \times 100$ & $\mathrm{~N}$ & $\frac{(e 7)}{(e 1) T 1} \times 100$ & $\mathrm{~N}$ & $\frac{(e 9)}{(e 1) T 1} \times 100$ & $\mathrm{~N}$ & $\frac{(e 11)}{(e 1) T 1} \times 100$ & $\mathrm{~N}$ & $\frac{(e 11)}{(e 1) T 1} \times 100$ & $\mathrm{~N}$ & $\frac{(e 15)}{(e 1) T 1} \times 100$ \\
\hline Total & (f) & $\mathrm{N}$ & $\frac{f 1}{(f 1) T 1} \times 100$ & $\mathrm{~N}$ & $\frac{(f 3)}{(f 1) T 1} \times 100$ & $\mathrm{~N}$ & $\frac{(f 5)}{(f 1) T 1} \times 100$ & $\mathrm{~N}$ & $\frac{(f 7)}{(f 1) T 1} \times 100$ & $\mathrm{~N}$ & $\frac{(f 9)}{(f 1) T 1} \times 100$ & $\mathrm{~N}$ & $\frac{(f 11)}{(f 1) T 1} \times 100$ & $\mathrm{~N}$ & $\frac{(f 11)}{(f 1) T 1} \times 100$ & $\mathrm{~N}$ & $\frac{(f 15)}{(f 1) T 1} \times 100$ \\
\hline
\end{tabular}




\section{Results}

\subsection{The GECOAGRI-LANDITALY survey itinerary applied to the European reality.}

To present the application methods of the GECOAGRI-LANDITALY survey, we will use only one of the characteristics of the methodology, the "structural" so defined because it investigates the functional organization of the territory through the farm and its constituent elements.

The use of this specific character is justified because the entire methodological system is based on the preliminary construction of the graphs of agricultural systems and related cartograms on a regional and national scale (empirical-descriptive phase); in fact, it is the different typology of agricultural systems that that highlight the potential and/or anomalies of rural areas, aspects that must then necessarily be investigated by examining the remaining characteristics (see paragraph 2). The graph of agricultural systems therefore represents the first, fundamental index - "alarm bell" and indicator-spy - of territorial peculiarities and problems; starting from its analysis, each rural reality can be more easily and adequately diagnosed / interpreted and / or treated with application proposals based in the subsequent phases of analysis and in the development of other indicators (see paragraph 2).

Here, for obvious reasons of space, rather than analysing all the characteristics of a single regional agricultural space, it was preferred to show how and to what extent the construction of the graphs of agricultural systems allows to compare different realities and to grasp the evolutionary trends in progress; we will therefore examine the structural characteristics of nine European countries, constructing the graphs of the agricultural systems of their regions. We would like to refer to those interested in following the entire survey itinerary, to the numerous studies that have applied it and that have been published by the inter-university research group $[33,34,35,36,37,38,39,40,41$ $42,43,44,45,46,47]$.

1) the percentage of the number of businesses out of the total number of businesses operating in the territory, divided by size classes.

2) the percentage of the farm area available to the farms of the different size classes (FA) on the total agricultural area of the examined territory.

3) the percentage of the area agricultural cultivated (CAA) by the farms of each size class on the total farm area of the territory (weighted CAA).

The graphic representation of the three different values restores "the agricultural reality of a political-administrative space", placing the agricultural company defined as "a real microcosm in which the problematic nature of the rural world is fully summarized" [48]; the combination of production units of various sizes on the same territory shows who and how much it is possible to produce, while the crop density (ratio between CAA and FA) of the different business size classes ${ }^{13}$ that characterize the agricultural system gives us the value of congruence ${ }^{14}$, of incongruity ${ }^{15}$ and the specularity ${ }^{16}$ of the different types of companies and the different systems. We will therefore define each agricultural system through two parameters: that of the size of the farm and that of the difference between the available agricultural area and the area cultivated.

The research and analysis potential of this methodological tool also appeared invaluable when we applied it to the study of agricultural systems in nine European states: Bulgaria, France, Germany, Greece, Italy, Portugal, United Kingdom, Romania and Spain. The choice of the level of analysis was

\footnotetext{
13 The farms were divided according to the amount of hectares owned. Micro farms (ranging from 0 to 2 hectares), small (2 to 5ha), medium (5 to 20ha), large (20 to 50ha) and macro farms (over $50 \mathrm{ha}$ ).

14 There is a situation of congruence when the difference between AAC and FA never goes beyond $5 \%$ in microcompanies, $10 \%$ in medium-sized companies and $15 \%$ in large companies.

${ }_{15}$ The inconsistency occurs when the difference between AAC and FA is between $5-10 \%$ in micro; $10-20 \%$ in medium and $15-40 \%$ in large.

${ }^{16}$ The mirroring of verification when the difference between AAC and FA always exceeds the thresholds indicated above (note 14) of the inconsistency.
} 
dictated by the geo-spatial classification of Eurostat NUTS2 ${ }^{17}$, which corresponds to the Italian regions, the German Regierungsbezirke, the Spanish Communidades autónomas and the French Régions. The data ${ }^{18}$ provided by Eurostat, concerning the hectares of cultivated areas (CAA), are in fact only available on this scale of detail which also allowed us to compare 171 regional agricultural systems.

It should also be noted that the level of analysis offered to us by NUTS2 is functional to the assessment of regional agricultural realities and, above all, to the formulation of usable proposals in relation to the application of local policies. The graph of the agricultural system has been constructed for each area examined and the comparison between the various graphs has highlighted the decisive prevalence of farms of larger size which cultivate less than $50 \%$ of their total area (inconsistent macro agricultural systems).

\subsection{The results obtained}

The 171 agricultural systems of the nine European countries analysed through the GECOAGRI LANDITALY methodology give us, at a first glance, a plurality of useful information to better understand the dynamics of agricultural structures both in terms of function and sector.

The predominant model of the agricultural system of the countries analysed by us results in being that of macros where the largest percentage of the Cultivated Agricultural Area (CAA) is concentrated in companies that own over 50 hectares. Then, with respect to the relationship between CAA and FA which gives us the crop density or how much of the land available to the farming business is actually cultivated, the prevalence of the typology of incongruent macro systems emerges (graph. 2b) (out of 171 agricultural systems analysed as many as 64 are incongruent or rather the difference between SAC and SAT is between 15\% and $40 \%$ ) followed by the specular model (graph 2c) and to a lesser extent the congruent one (graph. 2a).

The agricultural system characterized by macro farms indicates a predominance of farms over 50 ha and, above all, in the variations of inconsistency and speculation, alarm bells can be seen in relation, not only to land concentration but also to practice of the so-called "artificialization" where the land no longer acquires a land value but a financial one. The complexity of these phenomena always deserves further investigation starting from spatial variables and historical, social and cultural determinants, as the GEOCOAGRI LANDITALY survey methodology itself provides.

The prevalence of macro systems, for example, in some regions of Northern Europe (fig. 2) is the result of a plurality of factors ranging from environmental to territorial and political ones, such as, for example, the lack of land reforms aimed at to a more reasonable redistribution of cultivated land.

The graphical representation (fig. 2b) of agricultural systems in the United Kingdom, for example, is also justified because those territories, already starting from the medieval period, were the subject of a process of subtraction of land from farmers that intensified in the following centuries, as Kostrowicki [49] reminds us, "when the growing need for wool by the factories in Flanders made sheep farming highly profitable. Then the English lords began to gather their lands scattered among the fields of the farmers in compact blocks". The organization of the English rural landscape, therefore, due to its history and political and social dynamics, has assumed its own physiognomy and a clear identity characterized, in fact, by the wide dimensions of the estates the large company structure then corresponded. The problem in this case, in addition to the persistence of the macro corporate structure, declined towards the prevalence of speculation and incongruity, in the north-

\footnotetext{
17 The nomenclature of territorial units for statistics (NUTS) was drawn up by the statistical office of the European Union (Eurostat) in order to provide a single and uniform subdivision of territorial units for the production of regional statistics. The EU territory is divided into three different geographic levels: NUTS 1: includes the main socio-economic regions with a population of between 3 and 7 million people; NUTS 2: includes the basic regions for the application of regional policies with a population of between 800,000 and 3 million people; NUTS 3: includes small regions for specific diagnoses, with populations between 150,000 and 800,000 people.

${ }_{18}$ For the construction of the graphs of the agricultural systems, 2013 data from the Eurostat database was used, available on the page https://ec.europa.eu/eurostat/data/database
} 
western part, is also represented by its management. These types of farms are often associated with a cultivation not suited to food security but to energy. In Great Britain extensive large estates were destined to biomass [50].

In France (fig. 2c), where post-war land policy had favoured small farmers, there are currently some weaknesses that can be read through specular and inconsistent macro systems. Practices that can hide agricultural artificializations, as is currently registered in the French agricultural landscape where the land is subject to financial speculation and the land is changed in use to increase its value. The effects of these artificializations lead to land loss (over 60,000 hectares of agricultural land in France are lost each year) and to the structural change (in 1955, 80\% of farms had an extension of less than 20 ha, the current average is about 80 ha) as well as the loss of the workforce (from 2005 to 2016, according to Eurostat data, there was a percentage change in the number of employees in the primary sector of $-17 \%)$.

Germany (fig. 2a), which inexorably loses the number of farms (from 2005 to 2016 the loss was $25 \%$ ), also has a widespread macro-agricultural system and extended in the form above all of inconsistency. Here, too, in recent decades there have been practices of land concentration by foreign investors who invest not so much in agriculture but rather in bioenergy crops. This phenomenon is particularly true in East Germany where the privatization of state lands and the deregulation of the land market have favoured major investments by significantly increasing the value of land less and less suited to agriculture and increasingly to speculation.

The same phenomenon that occurred in East Germany can also be traced in the geographical realities like post-communist Bulgaria (fig. 2e) and Romania (fig. 2f), which have had a recent history of land fragmentation, where macro agricultural systems prevail.

The extension and persistence of the macro agricultural systems present in Bulgaria, all of which are highly speculative, require specific attention because this State, following the post-communist agrarian reform, has registered a land fragmentation which has, however, responded with a "reconcentration" ( $82.4 \%$ of farms are over 100 ha), favoured by local laws and strongly supported by new private landowners, financially strong, who bought large lands for speculative purposes that range from tourism, mining and industrial agriculture [51]. In this case, the structural organization of macro agricultural systems in the various forms becomes an indication for land concentration and land grabbing. In this regard, from the comparison with Eurostat statistics (2016), shows some data that confirm the distortions of the Bulgarian agricultural system: from 2005 to 2016 farms decreased by $59 \%$ while the agricultural area used increased by $60 \%$ losing, however, simultaneously and to the same extent $(60 \%)$, the workforce and an even more shocking data is that in 2005 there were 367,910 small businesses whose families consumed more than $50 \%$ of total production, of which, in 2016, there was no trace left. In the dual agricultural system (macro and medium) of Romania it is possible to trace the dynamics of the primary sector, starting from the post-communist phase which led to the dismantling of cooperatives with the result of family farming whose echoes can be traced precisely in the present landscape of medium-sized agricultural systems and industrial agriculture which finds its manifestation in the macro agricultural system, behind which those former officials of the regime who were able to use their networks to obtain access privileged to land privatization programs, accumulating it and then making it a speculative asset, as confirmed by some quantitative data (percentage change 2005-2016): decrease in companies (13\%), decrease in employees in the primary sector $(10 \%)$, a decrease in those businesses characterized by family farming (14\%). (Eurostat, 2016) [52].

The Spanish countryside also characterized mainly by macro agricultural systems (fig. 2d) and medium-large systems, where medium and large farms prevail (see graph. $2 \mathrm{f}$ ), has been suffering for some years from an important land concentration. The detailed study on the Andalusian case (graph. $2 b)$ clearly exemplifies the problems of Spanish agricultural: decrease in farms, increase in their size, abandonment of land by small owners, consolidation of land ownership. All problems that can be read in the graphic representation of the Spanish agricultural systems between speculation and inconsistency [52]. 
From the monotony of the macro systems that have absorbed the landscape of some Northern European states making them structurally univocal and in some ways homologating, we move on to the changing Italian structural types (graph. 2d) and Portuguese (graph. 2e, 2h) and those of Greece's small and medium-sized congruent ones.

The cartography (figs. 3a, 3b, 4) gives us an image of a spatial distribution of medium-small and micro systems linked, therefore, to Southern Europe (graph. 2g, 2h, 2i, 2m). In particular, Greece becomes a sort of paradigm state where the congruity of micro and small systems can be observed (graph. 2i, 2m). This type of system is becoming a rara avis in the European landscape, not only for the type of medium-small and micro but also for congruity. We can find confirmation of this congruity in Eurostat data (2016) relating to the percentage change of companies that consume more than $50 \%$ of the final production from their farms: from 2005 to 2016 they increased by $300 \%$.

Italy is a laboratory where you can observe the different agricultural systems: from macro to medium-small. The regional scale certainly does not allow us to be able to analyse in greater detail any dystonia that instead occur on a larger geographical scale, as we have seen in other studies [54]. We limit ourselves to highlighting some macro elements of dystonia that may, in part, reflect the structural organization of the Italian countryside starting from speculation and incongruity of most of the agricultural systems that are declined towards the type of medium-large thus that micro-small pattern - the only proof is Genoa, albeit specular - which has distinguished the Italian agricultural reality, guaranteeing quality and typical characteristic. The decrease in companies (from 2005 to 2016 there was a loss of $-32 \%$ ), in particular of micro companies, the negative percentage change in the workforce (years 2005-2016 equal to -36\%) and in family farming are the signs of a latent and inexorable decline in the primary sector.

The diachronic analysis of European agricultural systems confirms the important land dynamism to which, for some decades, the countryside of the old continent has been exposed, increasingly homologated by the land concentration process both in the structural organization of farms and in the forms of the rural landscape [55].

To show in all evidence the acceleration of this phenomenon is the comparison between the cartographic representation of European agricultural systems at the beginning of the nineties of the twentieth century and the end of the first decade of the third millennium (Fig. 5 and 6). The two images show, in a lenticular way, the transformation of the countryside into a North Atlantic Europe characterized by macro agricultural systems, which are contrasted by the medium-small and microones of Mediterranean Europe. A structural and functional variety (Fig. 5), expression of historicalcultural traditions and different political events, which has been gradually erased. Micro farms, the icon of southern European countries, have been absorbed by medium-large ones, as shown in the second cartogram (Fig. 6), and the biodiversity of typical local crops has been sacrificed to monocultures that have made the costs of exercise, optimizing yields and, however, removing the farmers away from the countryside; in other words, by sacrificing territorial functionality to sectoral functionality. 


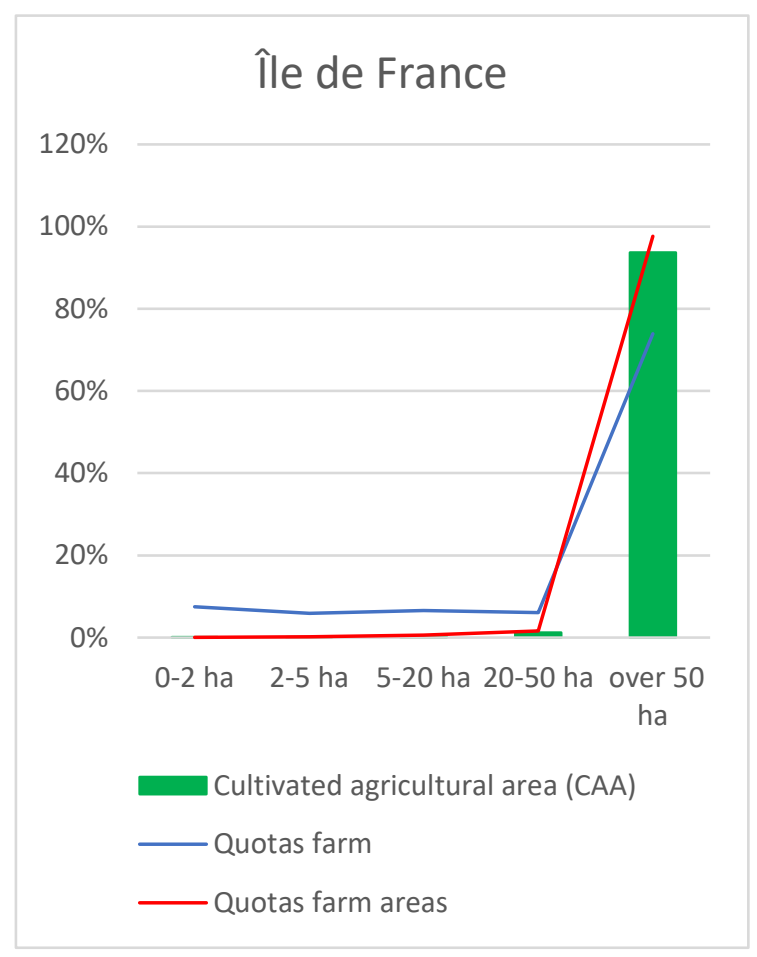

(a)

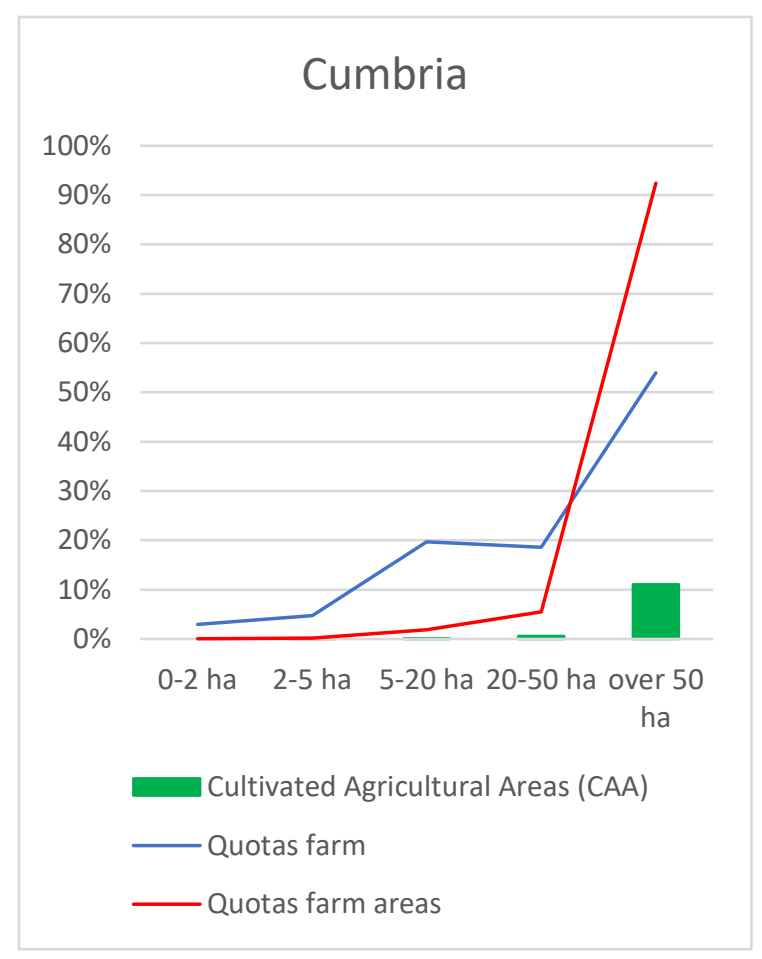

(c)

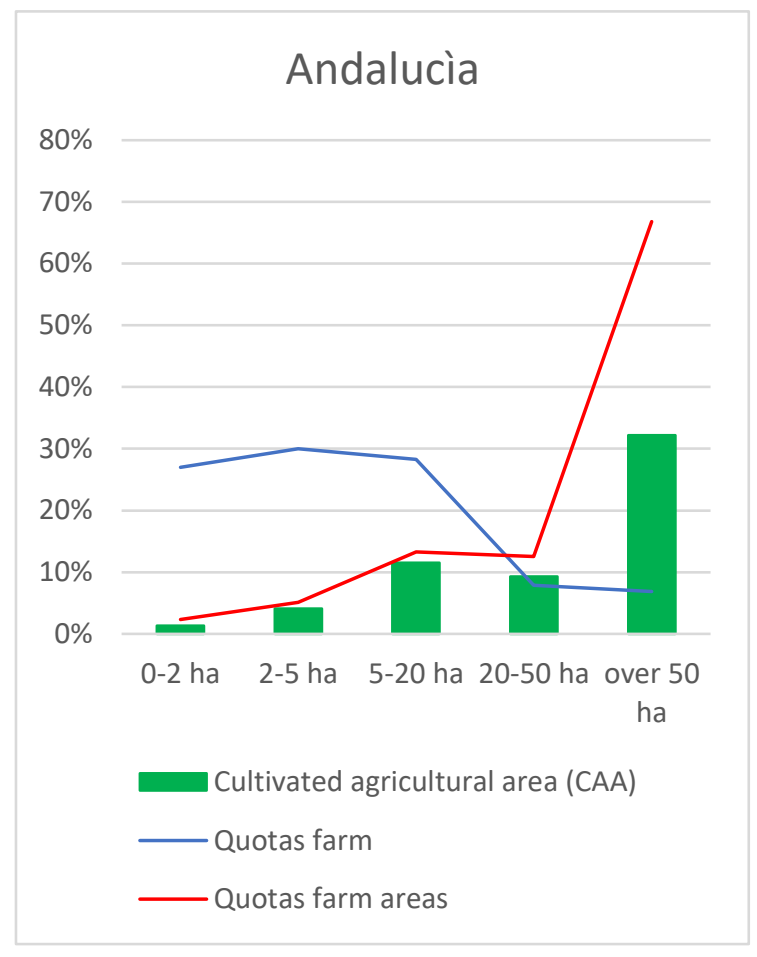

(b)

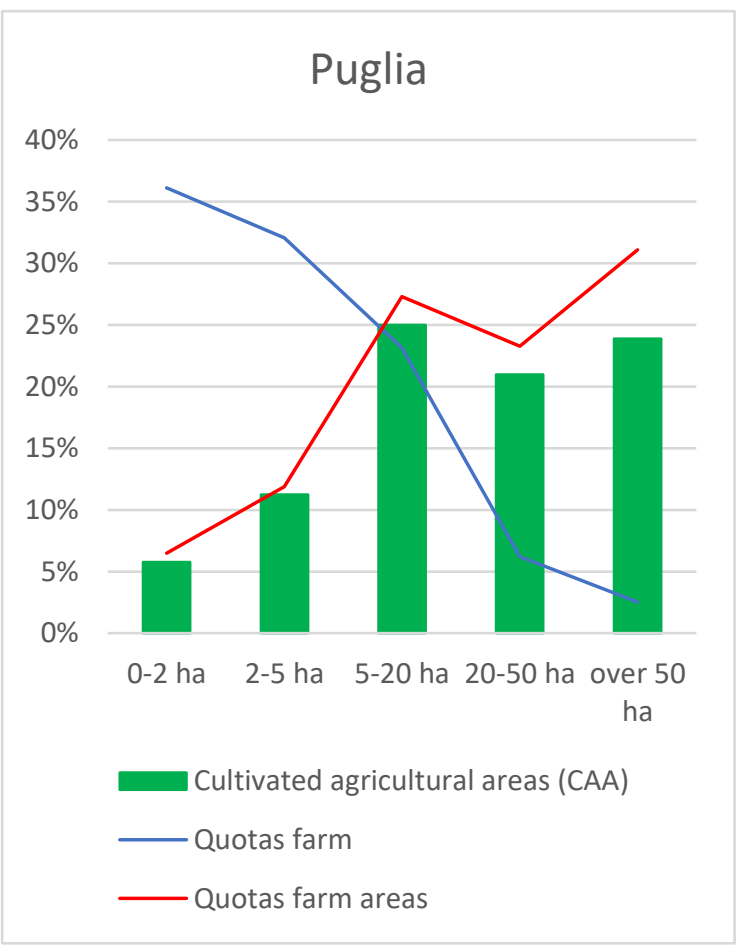

(d) 


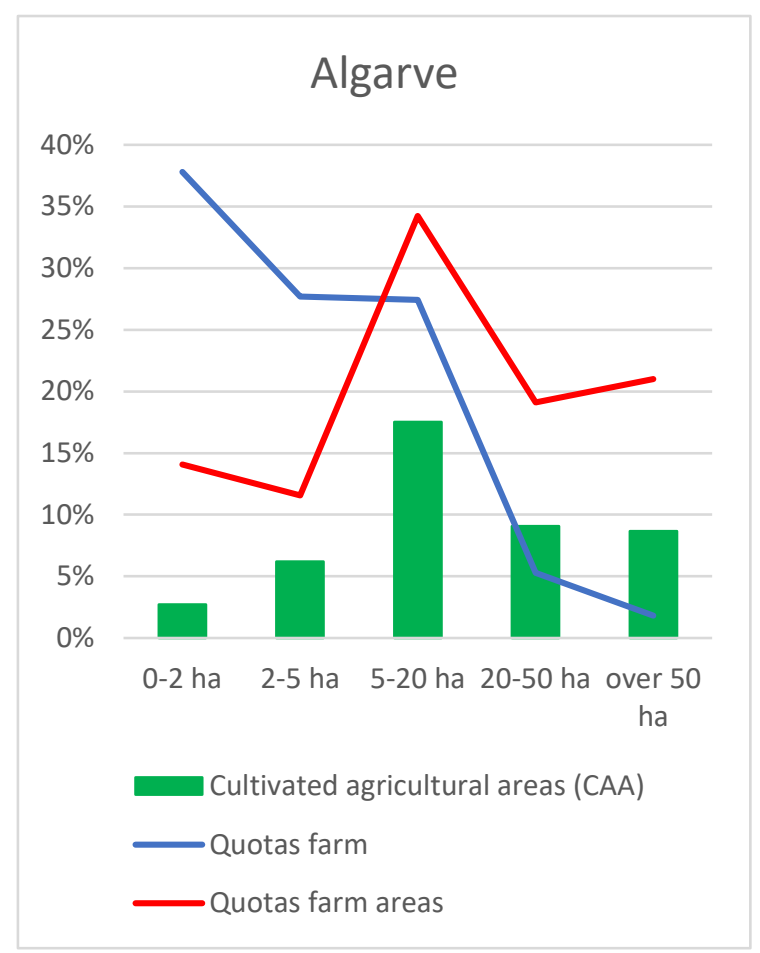

(e)

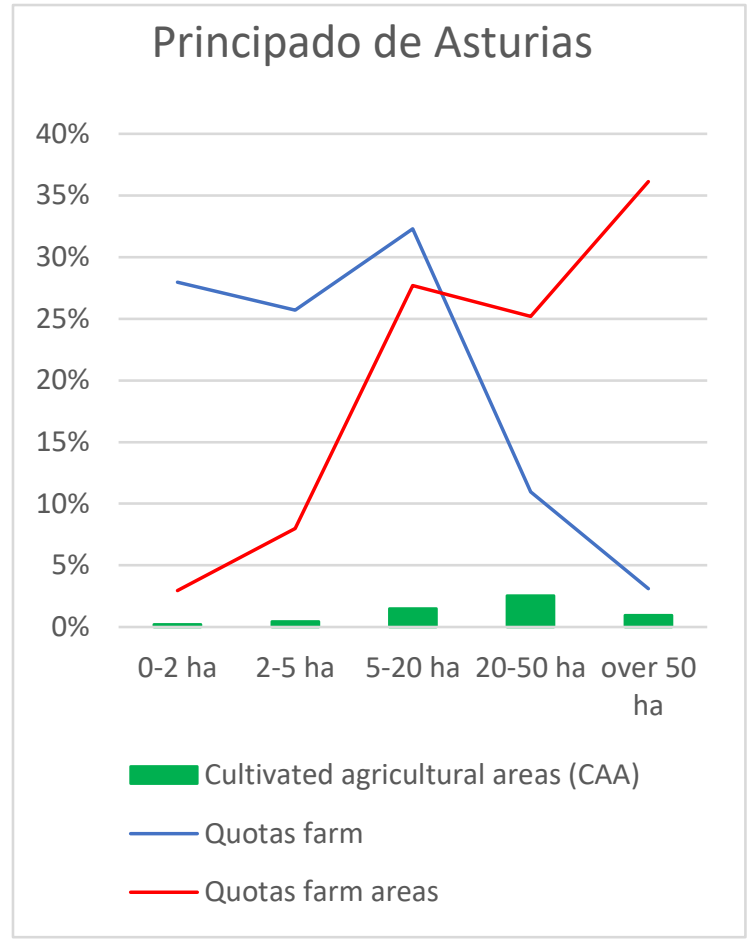

(f)

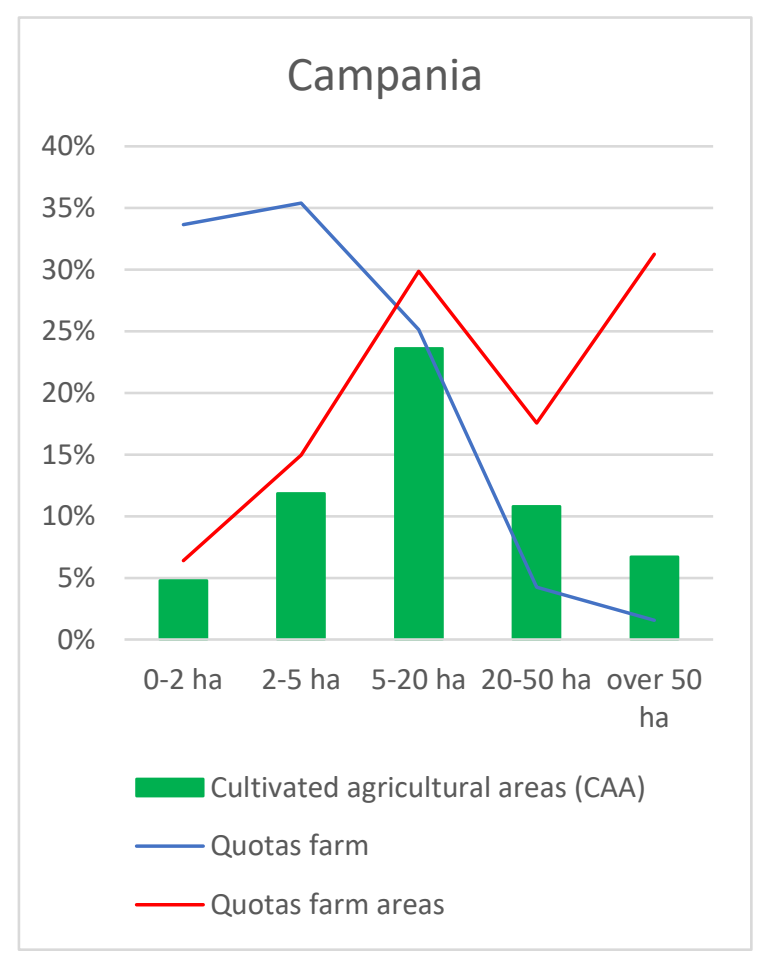

(g)

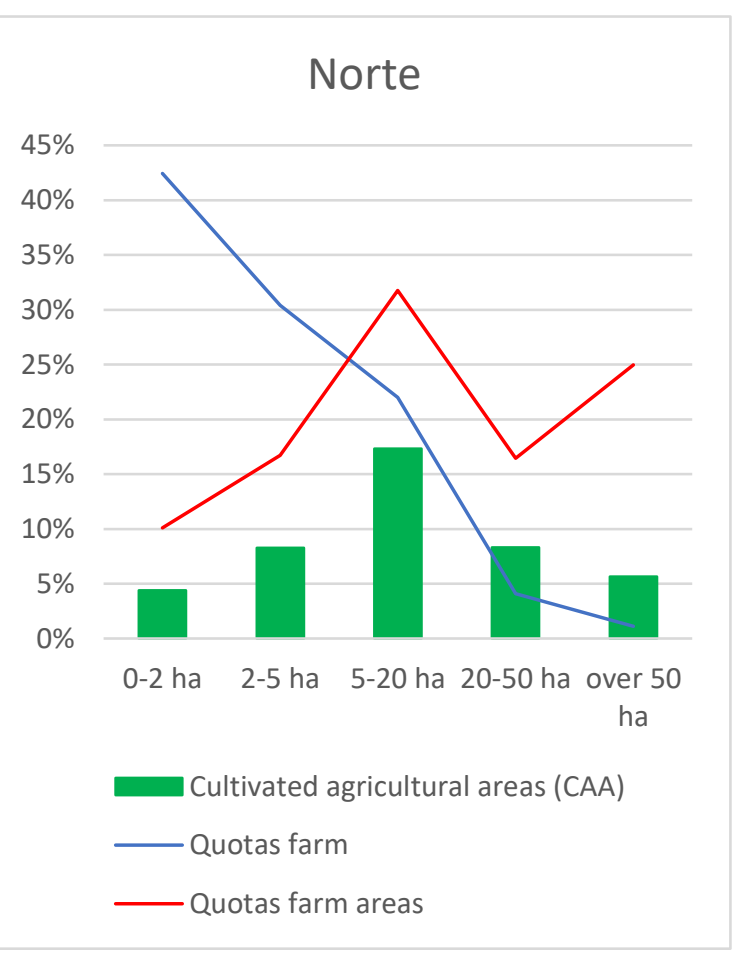

(h) 


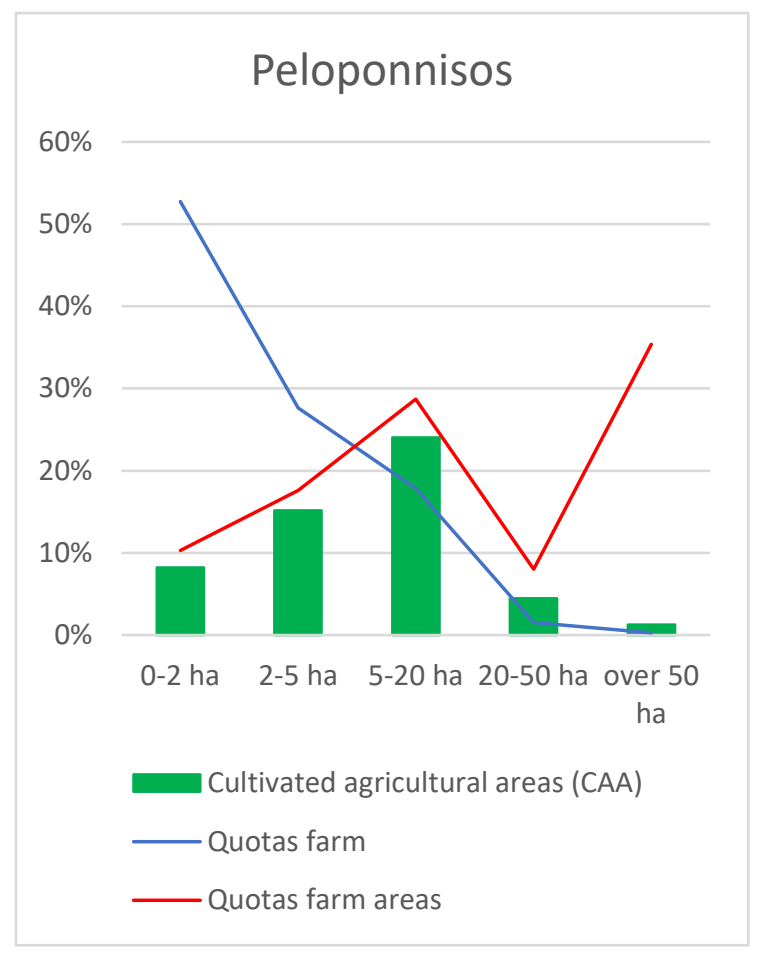

(i)

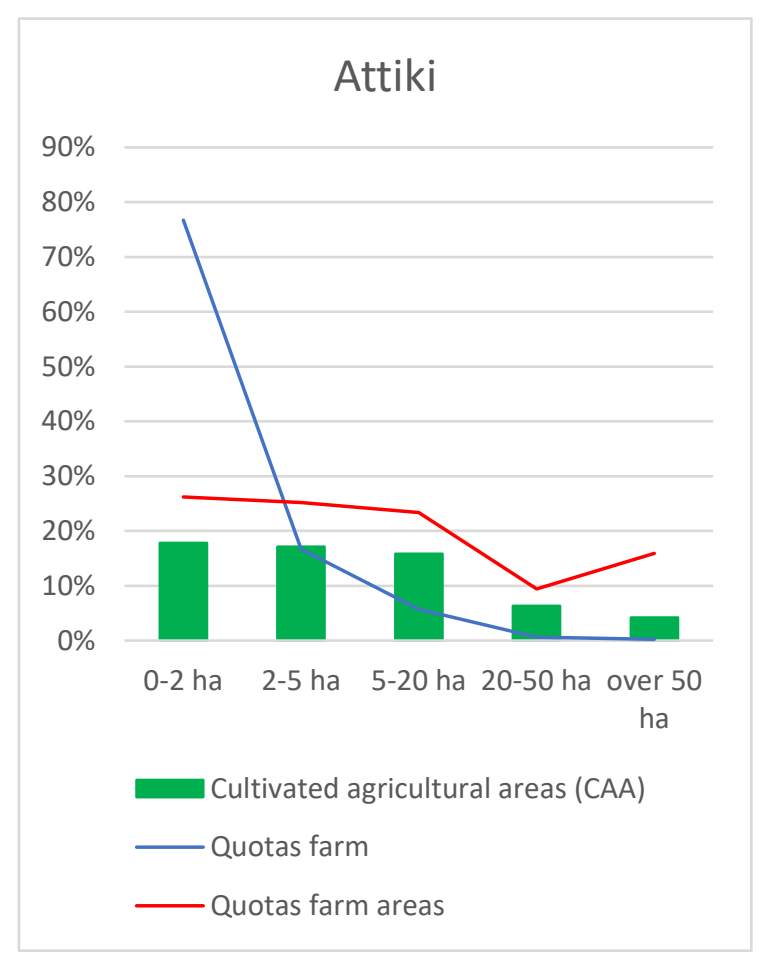

(m)

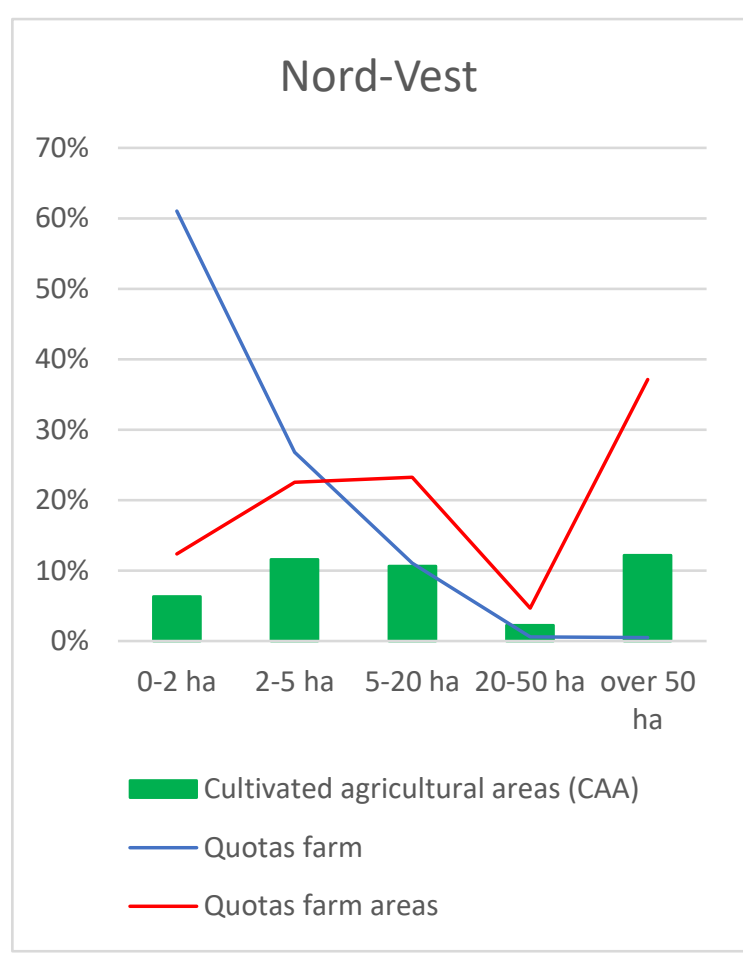

(1)

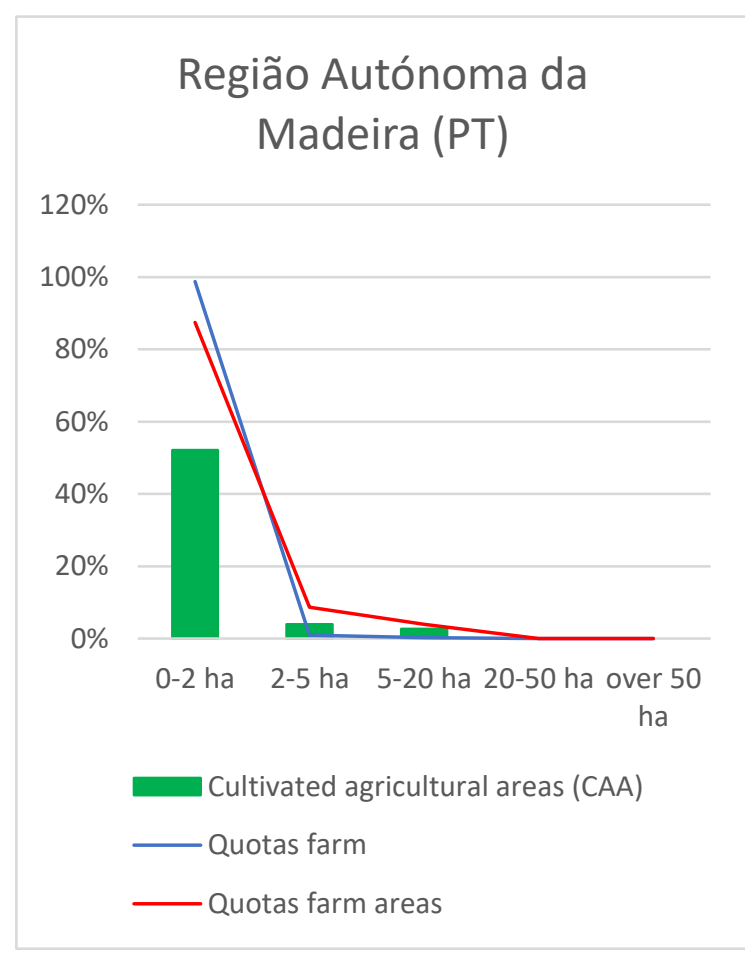

(n)

Graphic 2. The agricultural systems of some European countries. EUROSTAT data (2013), processed by the Author using the GECOAGRI LAND ITALY methodology 


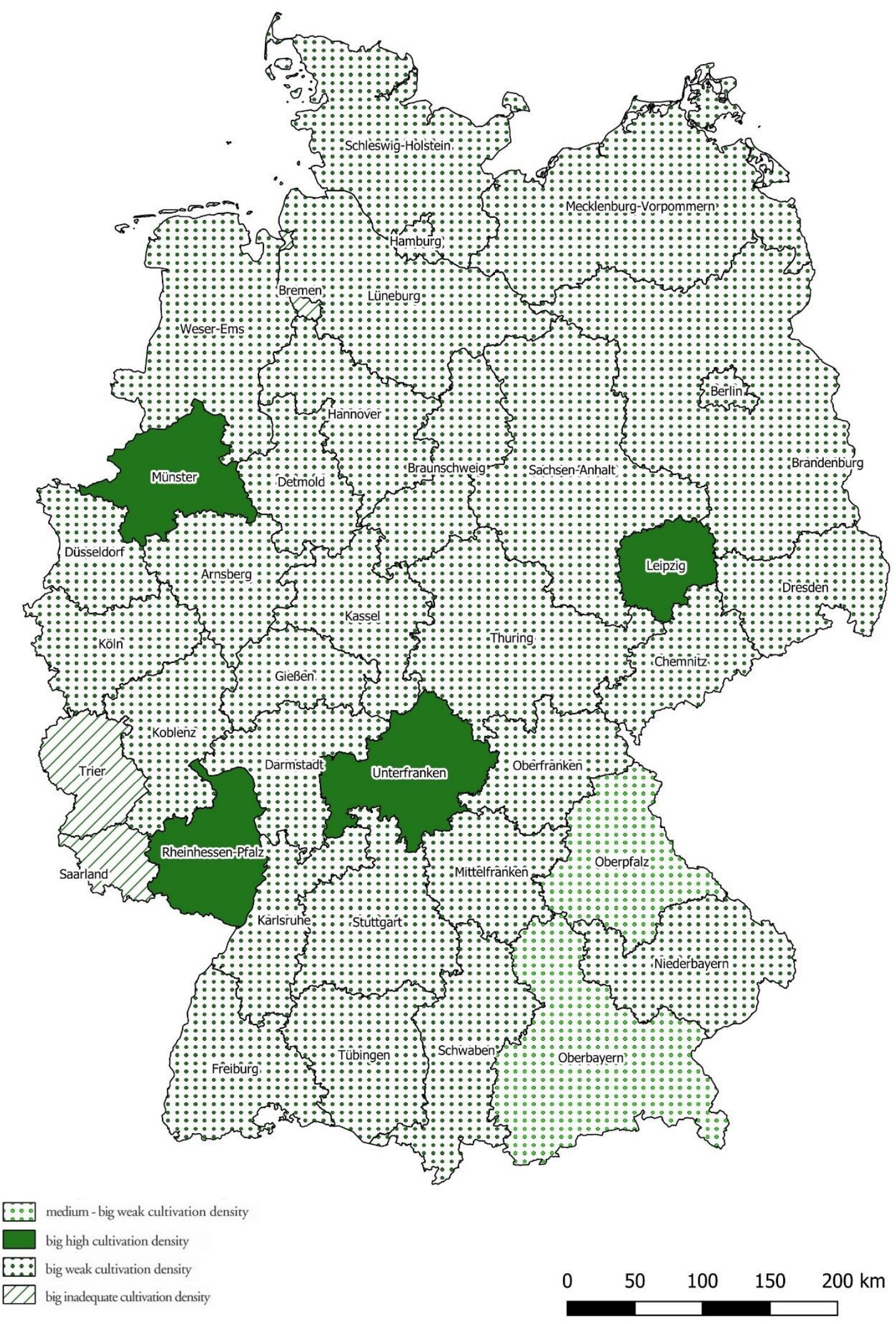

a - Types of agricultural systems in Germany 


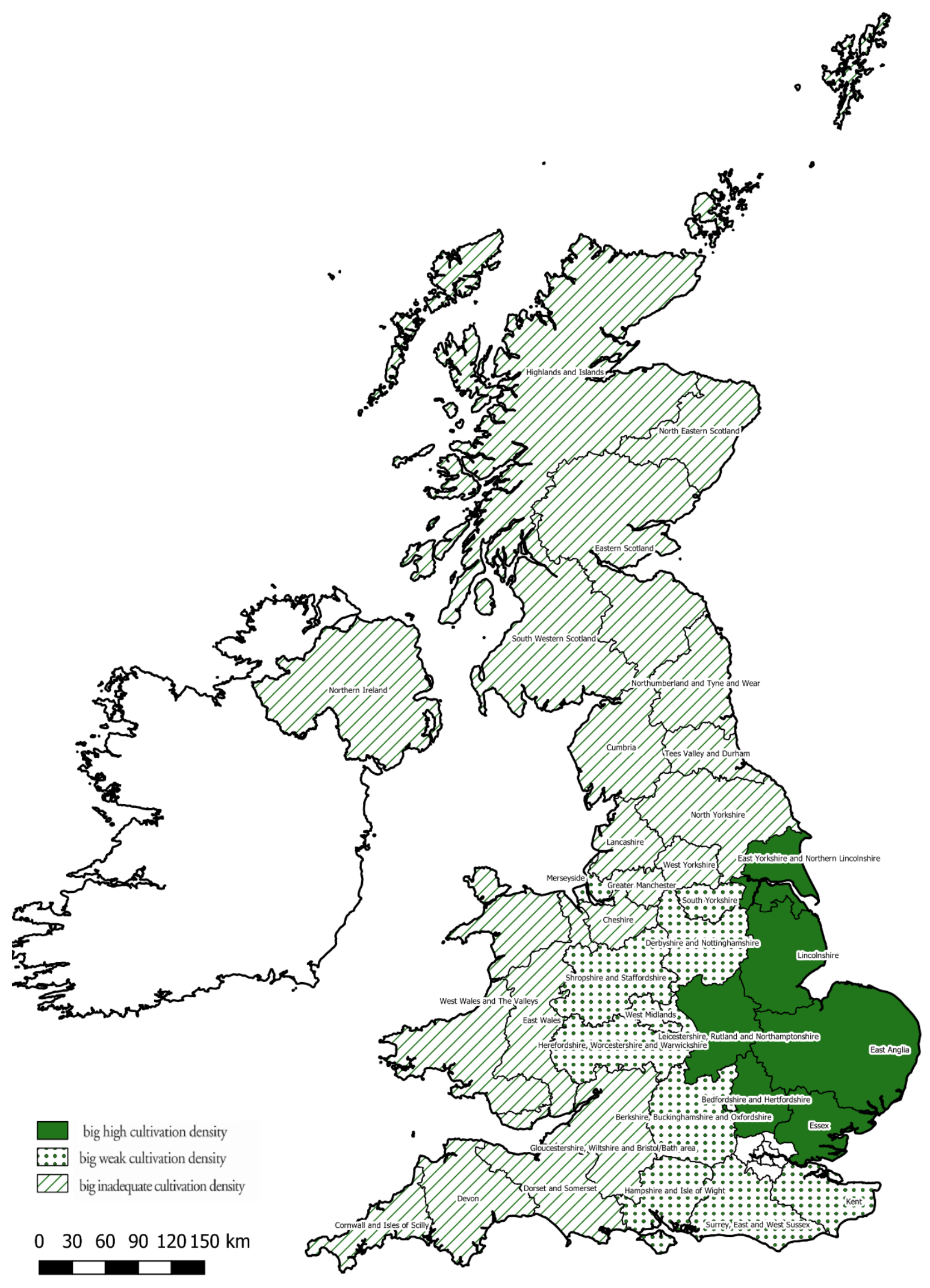

b - Types of agricultural systems in the United Kingdom 


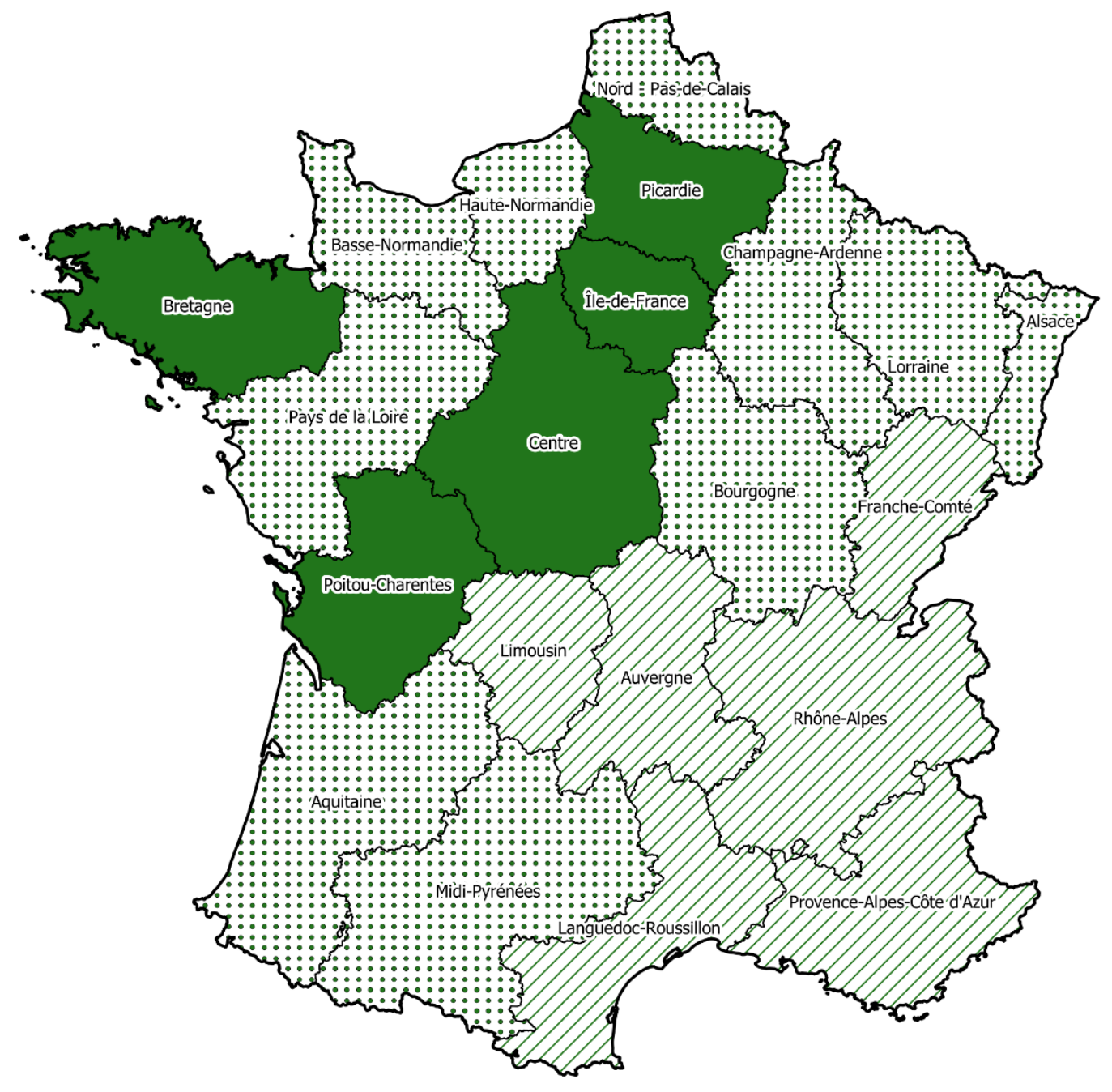

big high cultivation density

$\therefore:$ big weak cultivation density

$\square]$ big inadequate cultivation density

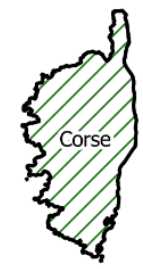

c - Types of agricultural systems in France

0

$100 \quad 200$

$300 \mathrm{~km}$

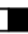




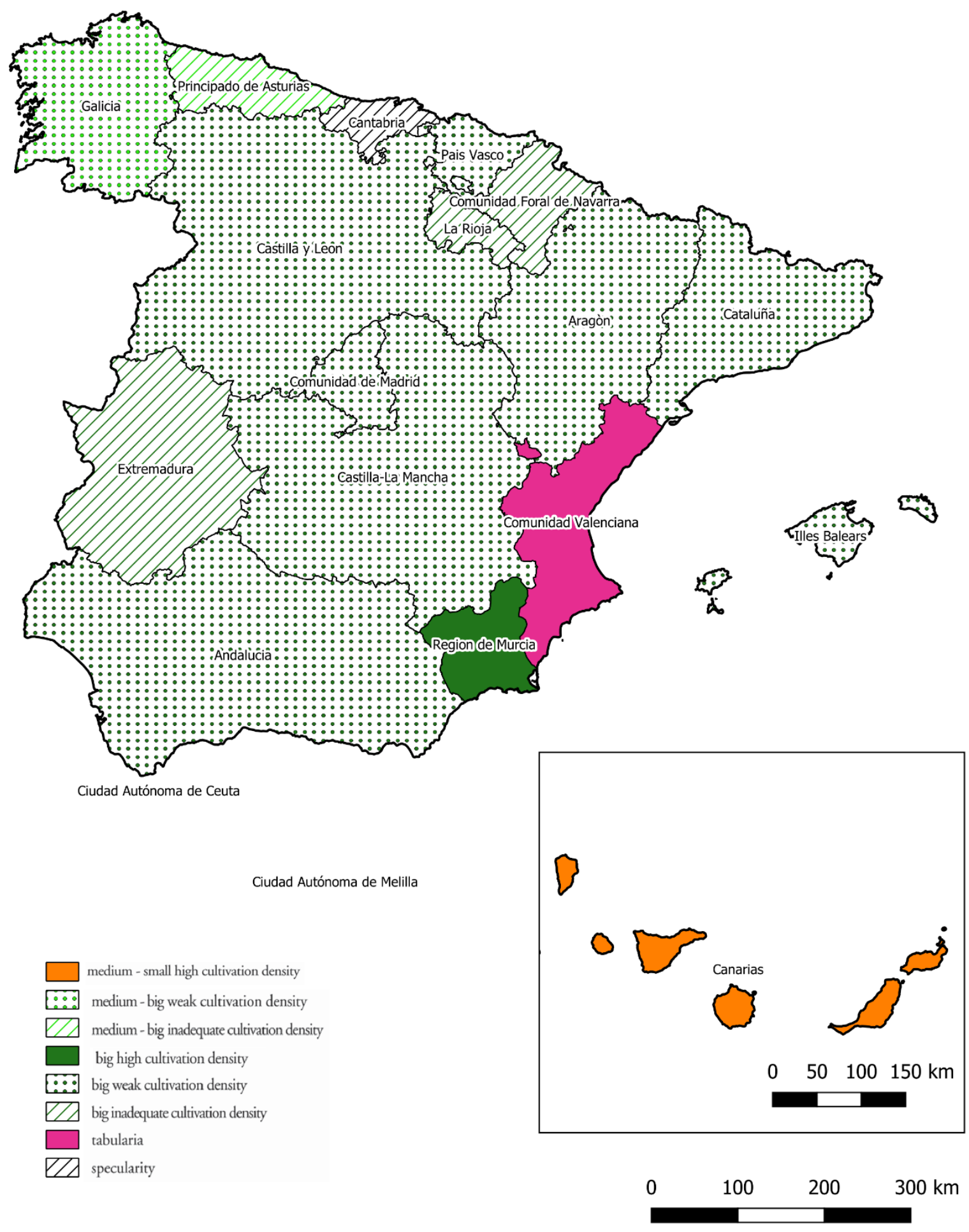

d - Types of agricultural systems in Spain 


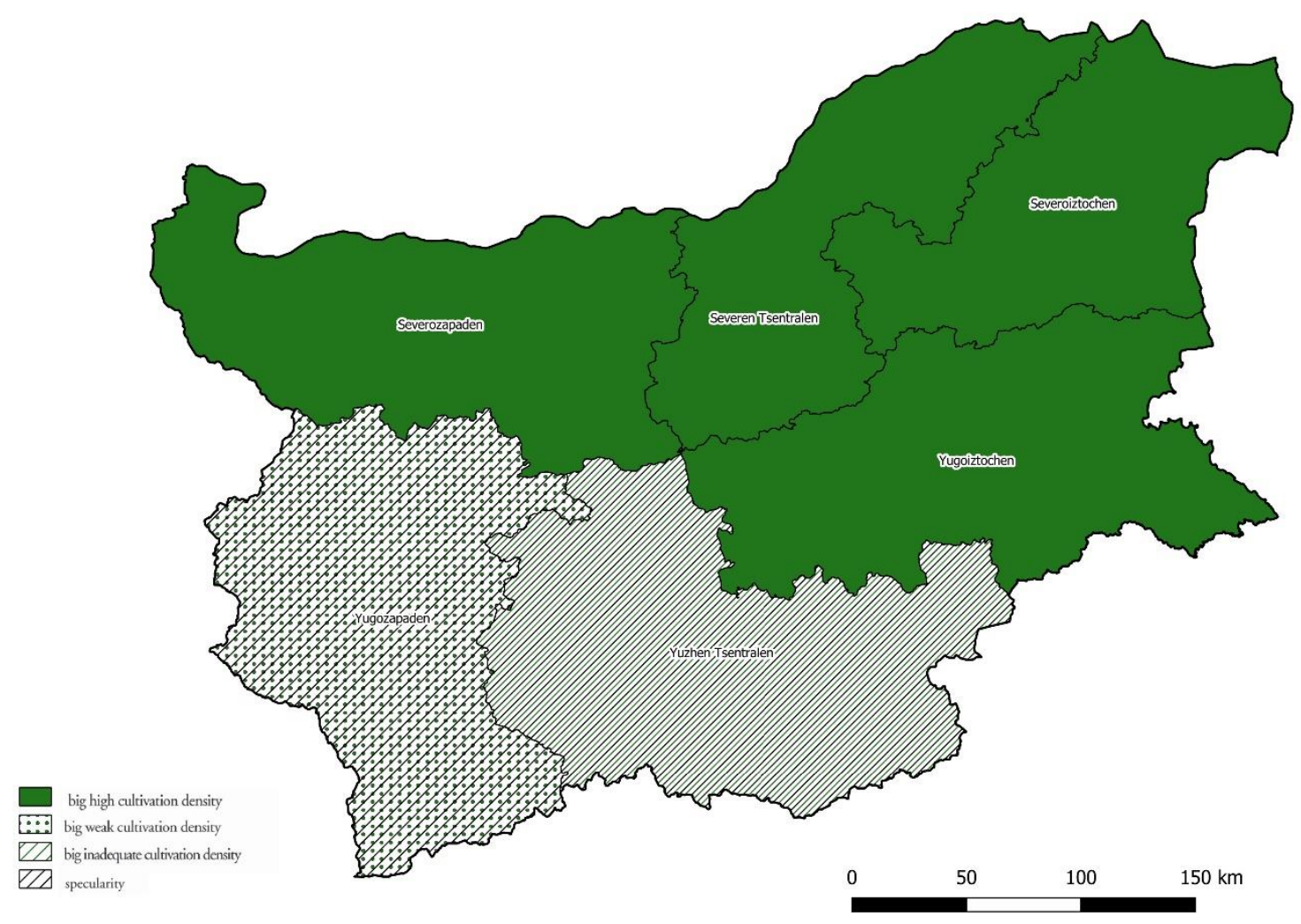

e) Typology of agricultural systems in Bulgaria 


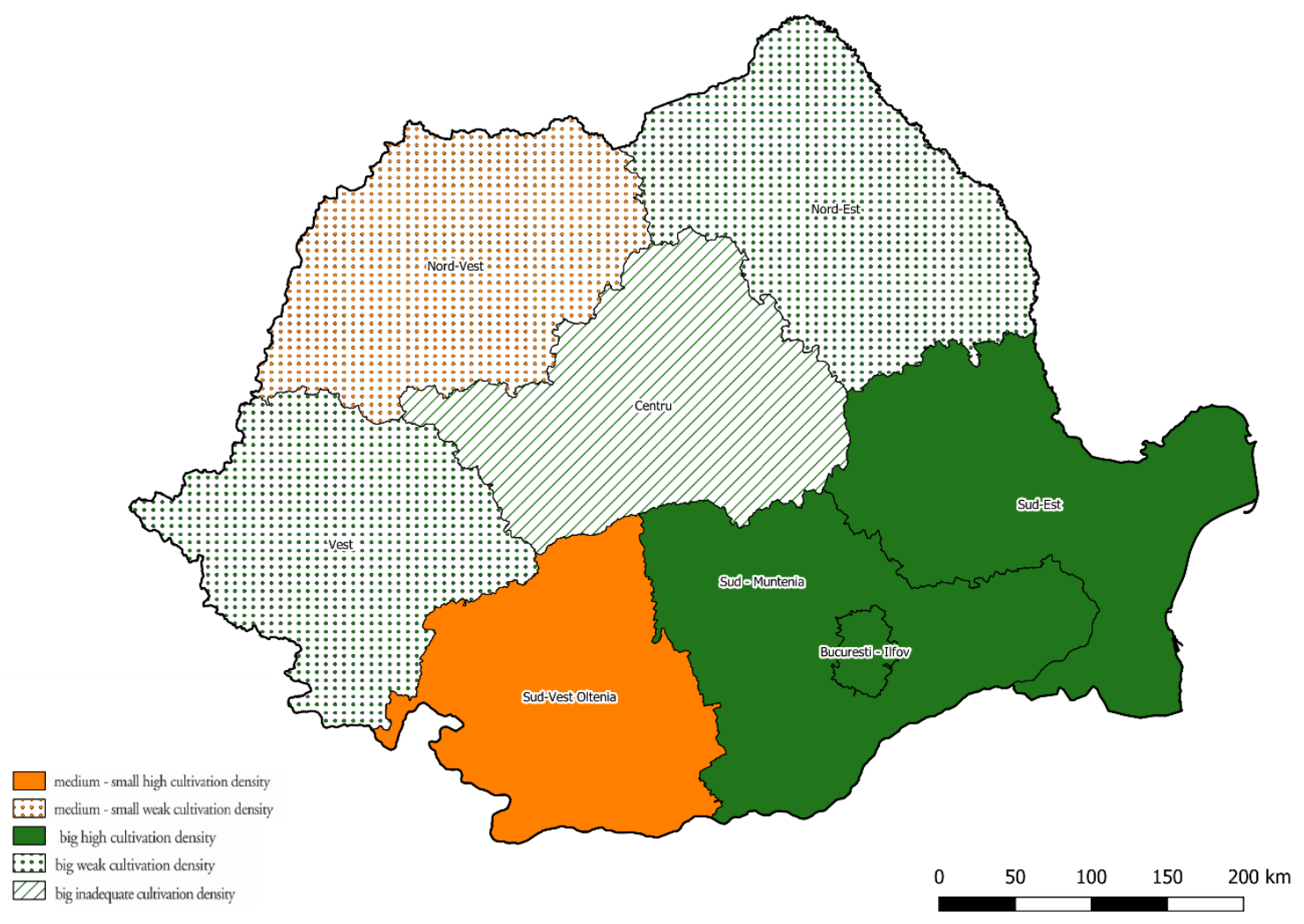

f) Typology agricultural systems in Romania

Figure 3. The European countries where the macro agricultural system predominates. Eurostat (2013). Cartographic elaboration by the author. 


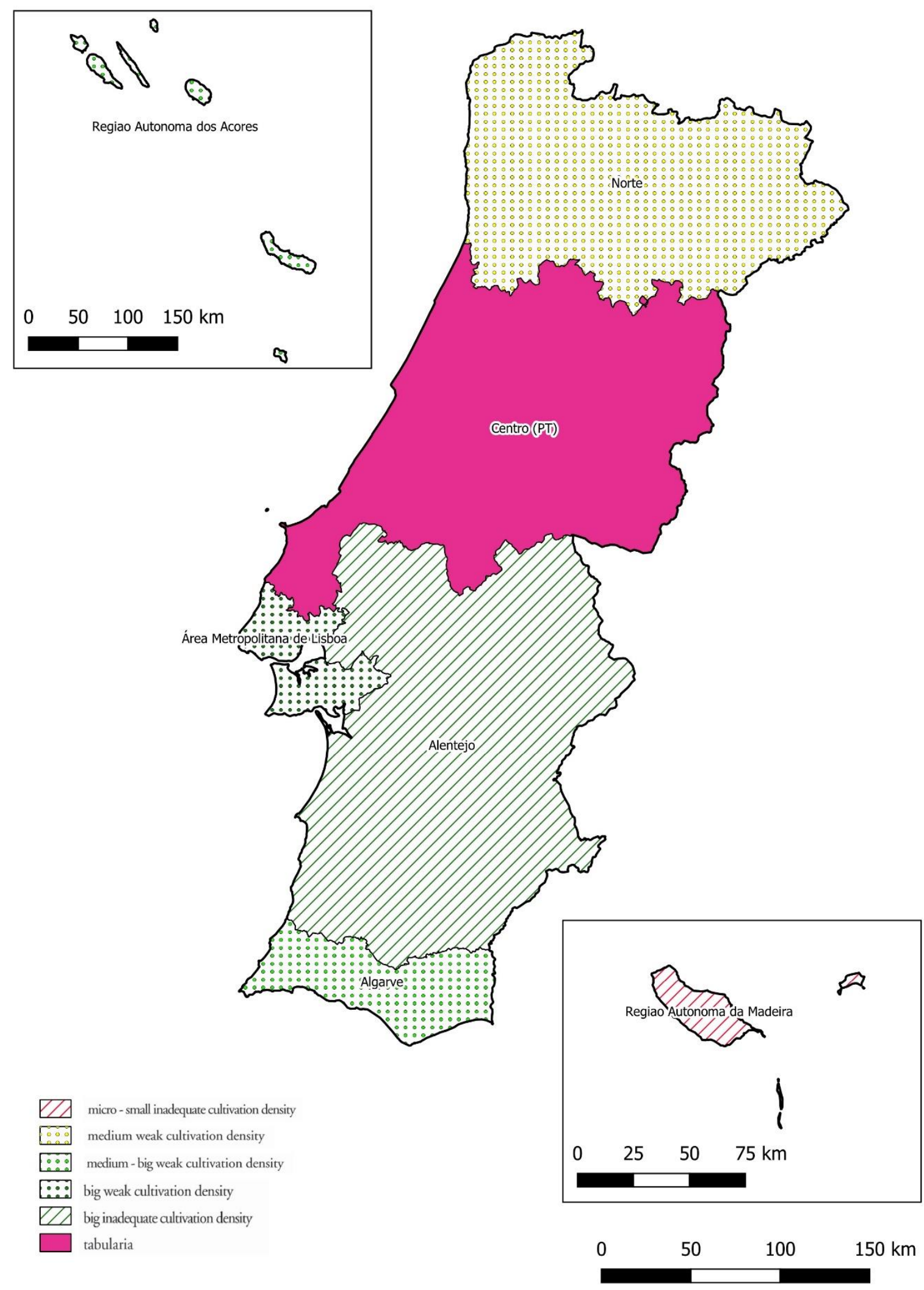

a) Agricultural system of Portugal 


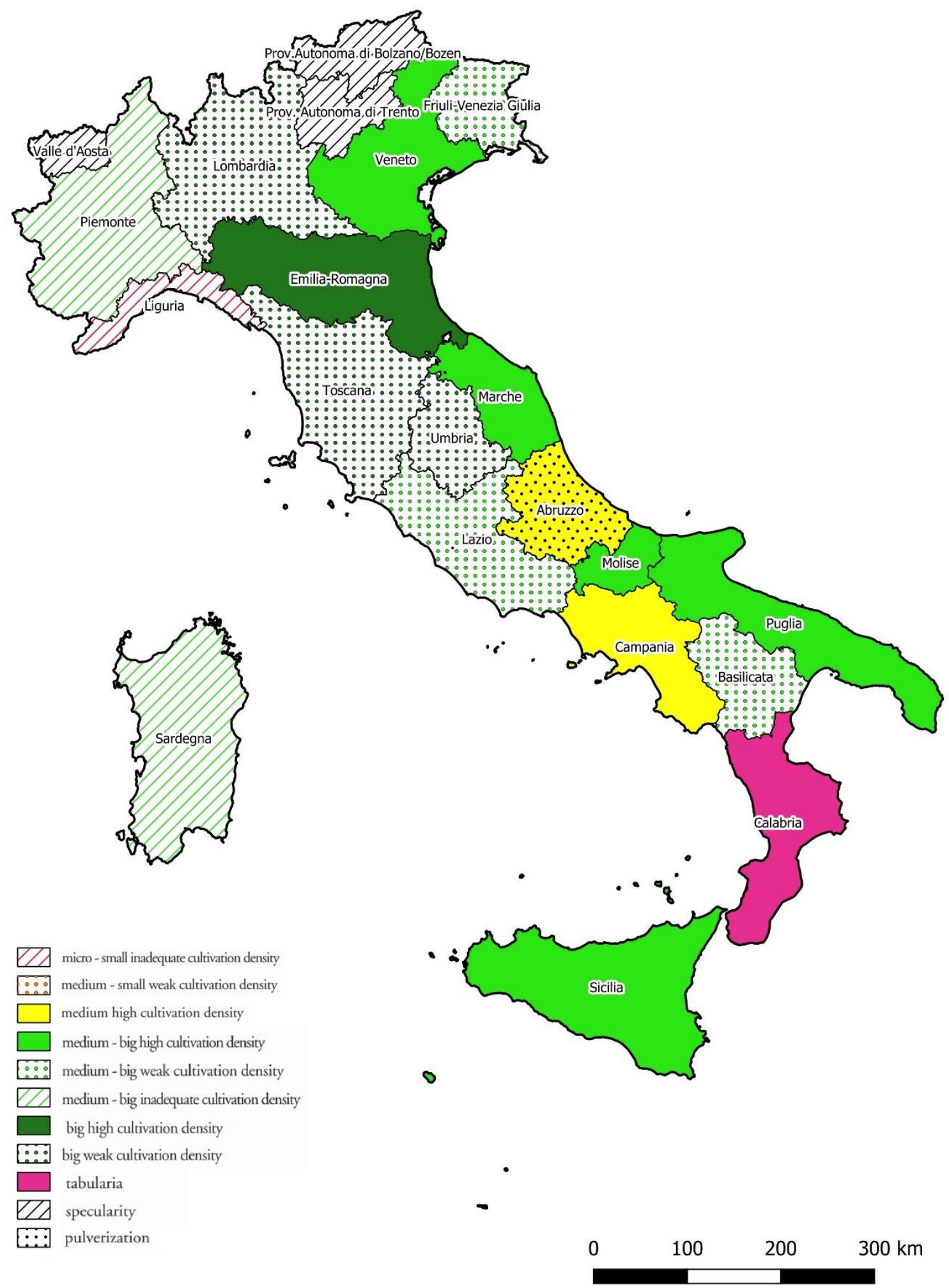

b) Agricultural system of Italy

Figure 4 - The European countries where the medium-large agricultural system predominates. Source: Eurostat (2013). Cartographic elaboration by the author. 


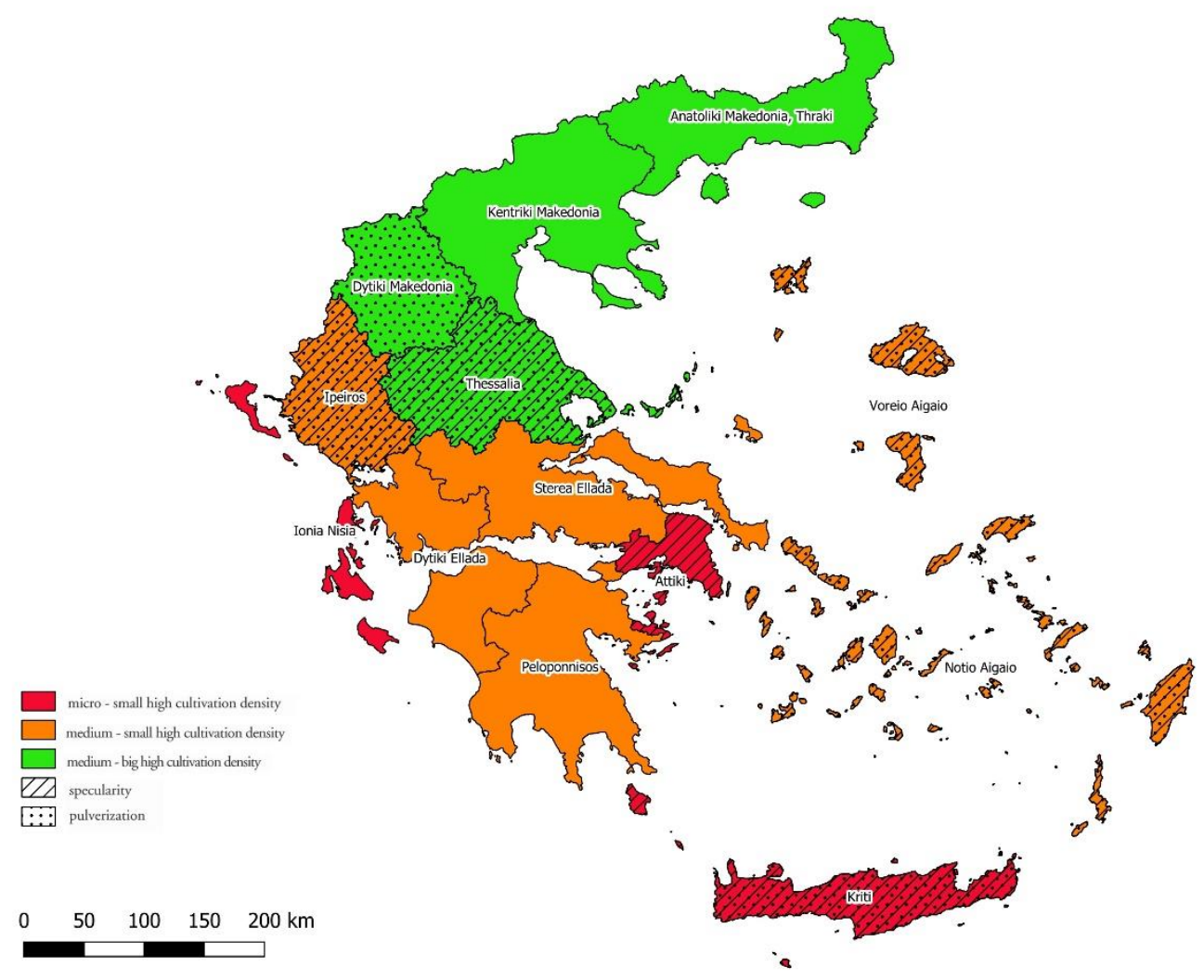

Figure 5. The European state of Greece where the medium-small agricultural system predominates. Eurostat (2013). Cartographic elaboration by the author. 


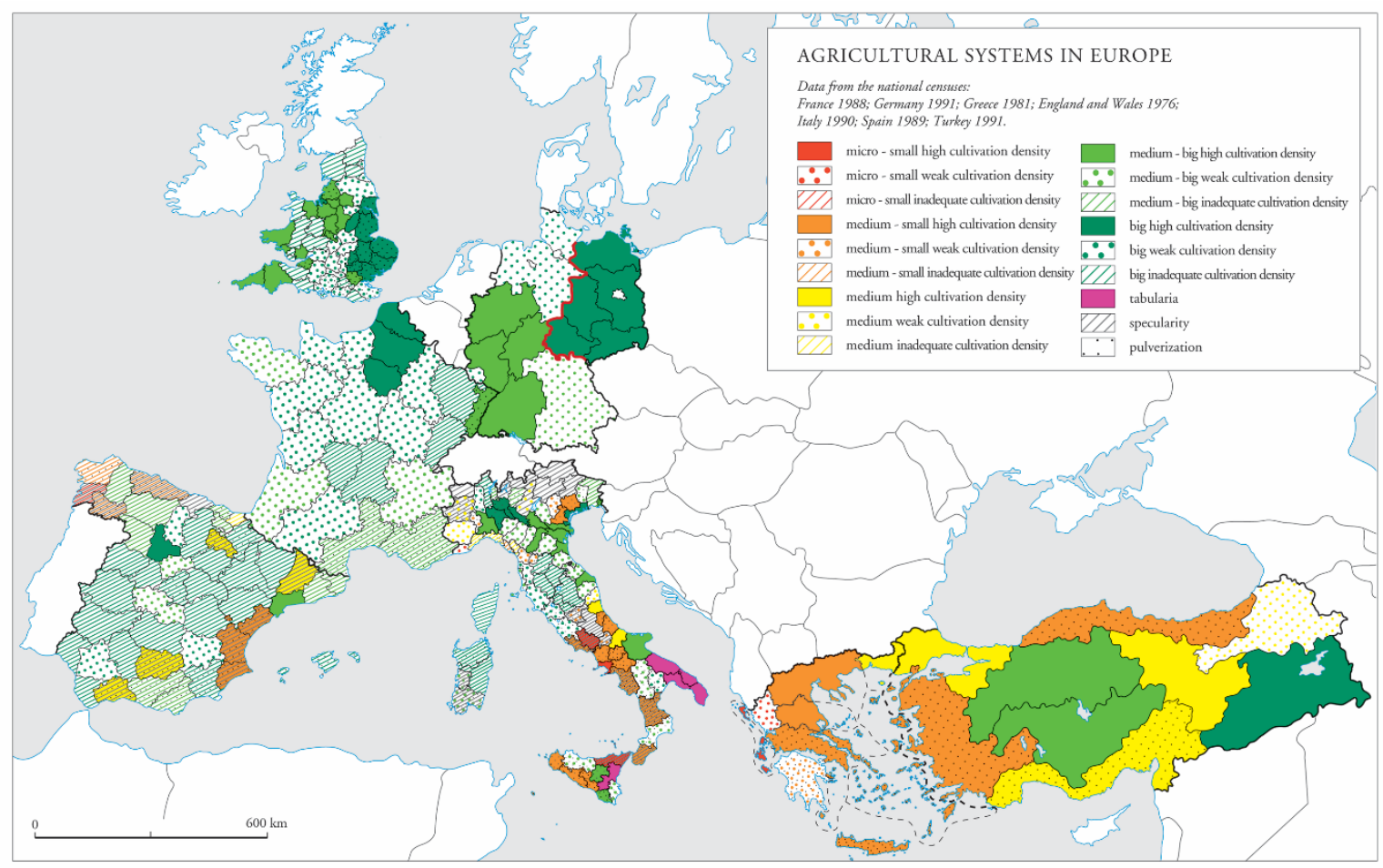

(sources: INSEE, 1998; Statishisches Bundesamt, 1991; NSSG, 1989; HMSO, 1976; ISTAT, 1990; INE, 1989; T.C. Basbakanlik Devlet Istatistilk Enstitütü, 1991)

Figure 6. Agricultural Systems in Europe, 1998 [54]. 


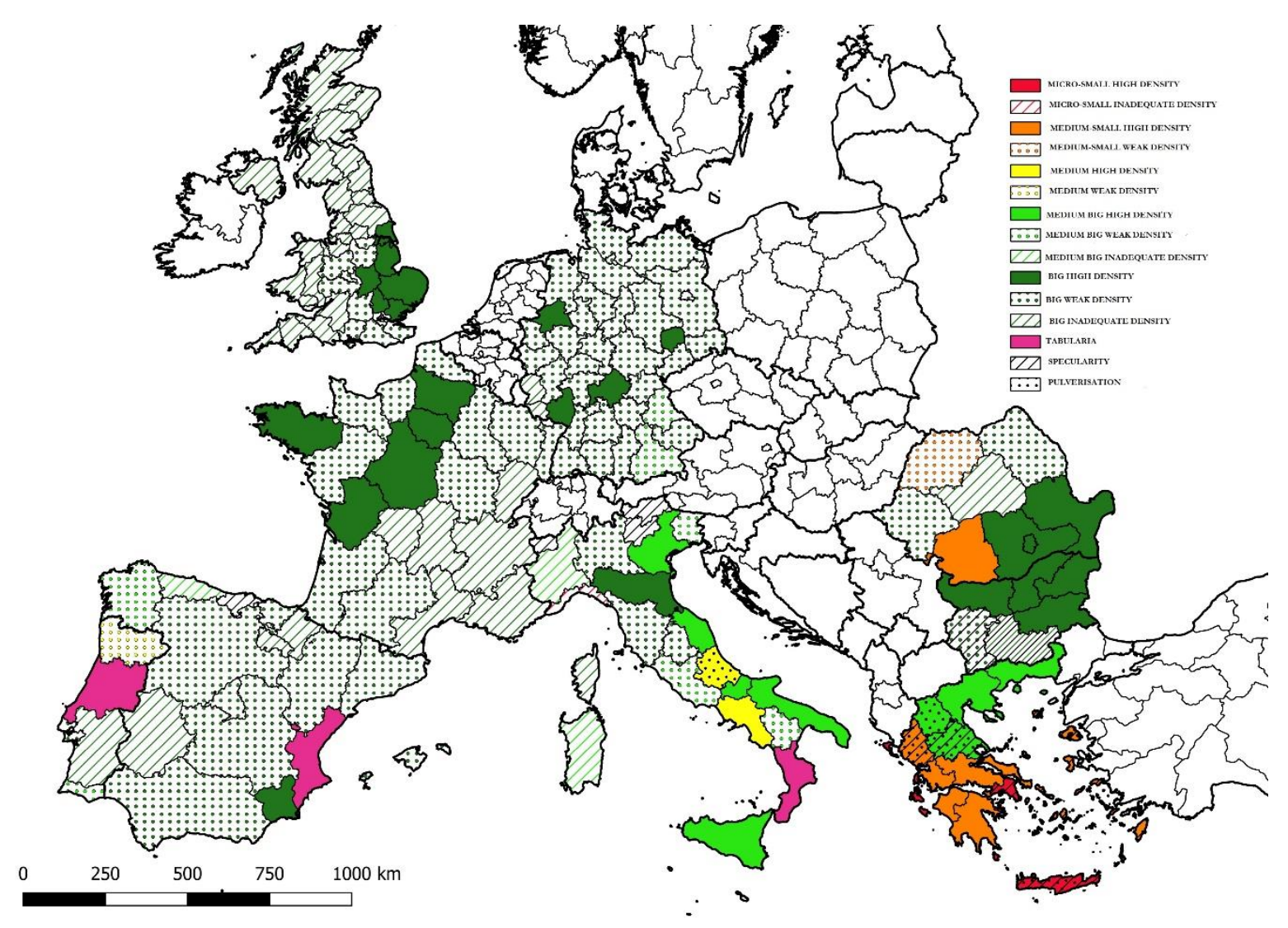

Figure 7. Agricultural Systems in Europe. Eurostat (2013). Cartographic elaboration by the author

\section{Discussion}

The diachronic analysis of the European agricultural structural characteristics systems has highlighted the process of land concentration that in recent decades has been expanding from north Atlantic Europe to the Mediterranean (cf. Fig. 1 and 2), so let us ask ourselves if, where and how it will be possible to build a new city-country relationship and the necessary function of the "agricultural places".

Until now, as mentioned in the first paragraph, the city has played a decisive role in the creation of food models and the countryside has played the equally fundamental role of creating typical products, preserving and ensuring their quality [56,57,58,59,60]. For some years, however, it has been the same international bodies, responsible for tackling the food problem, to focus on rethinking the relationship between city and countryside or, better said, between urban food demand and supply from agricultural production. In fact, on the one hand, the urbanization process is worrying which, according to projections, will lead three quarters of the world population to live in urban agglomerations by 2050, while, on the other hand, it appears increasingly clear that food security and sustainable development are and will be the countryside and agricultural operators (see GFFA Communiqué 8 th Berlin Agriculture Ministers' Summit 201616 January 2016).

So let's ask ourselves which farmlands will be able to best perform this function by ensuring, guaranteeing the quality and typicality of traditional foods. On the basis of the investigation itinerary that we have presented (see paragraphs 2 and 3), we begin by emphasizing that it is not at all difficult to recognize the territories prey to land concentration dominated by annual monocultures and intensive livestock housing - undoubtedly not very attractive if not even desertifying - and that, on the other hand, it is even easy to recognize those agricultural areas that have best known how to preserve biodiversity and cultural traditions; on the contrary, we observe that it is the harmonic forms 
of their rural landscapes that document this and attract the attention and interests of the urban population.

Therefore, if until now it has been the cities and centres of power to process the agri-food demand and to impose the products they have chosen on the global market, through the advertising of the "traditional specialties of quality", it is now necessary to take note that these productions, if and precisely as typical, can only be "rare and scarce". Their value lies in being strongly localized, obtained in specific and circumscribed territorial areas, to which we must return to enhance its uniqueness and from which we must start to know what range of distribution and consumption is really possible to establish.

We must not, indeed we can no longer start from the city neither from demand but, reversing the direction of this relationship, we must start from the countryside and its offers to re-educate consumption. Every food product that deserves the title "typical of quality" is in fact necessarily / constitutionally "limited" in time and space; and it is precisely these two categories - expressed by the individual places and by the alternation of the seasons - that give it value and uniqueness. If it is true, as Virgil already warned that "everything cannot give all the lands", it is equally true that the same food cannot have the same "taste" if it is produced in places with different geomorphological characteristics and at different times of the year (the case of many dairy products can be used as an example, not unique but emblematic.

We know well that the city lives different rhythms from the seasonal ones; it consumes and asks to consume day and night in all months of the year, nor are the markets willing to limit this demand, always ready, everywhere and in any case to give it a rather adequate answer. The exploitation of local food policies by the global market therefore constitutes a concrete risk - food, economic and political - from which it is possible to protect oneself only by rediscovering the cultural and cultural peculiarities of our countryside. The problem of the relationship between global and local is actually the same one that contrasts the proposals generated by the city with the offers guaranteed by the countryside.

A contrast that has commercial and, above all, political value because if on the one hand niche foods are exalted, strongly rooted in the traditions and micro-environments of individual local realities, on the other hand, global overexposure of advertising on a planetary scale can even play a less important role unfavourable to the protection of typical local products. This happens in at least two cases: the first is when the promotion is so successful that the price of the specialty rises, so that it is exported and sold only far from the place of origin (table grapes of Ortona) and it is absurd not being able to taste the product on site; the second case is when the breadth of market demand exceeds local production capacity to the point of encouraging imitations and counterfeits so that, for lessees and local administrators, it becomes increasingly difficult to defend it, even from brands and labels rich in informative details.

However, it is possible to reconcile the two levels of consumption combining the values and quality of the place with the demand for food formulated on a global scale: farmers, traders and, above all, researchers who work in various ways in the primary sector will have to learn to know and interpret the originality of rural spaces, starting with protecting and enhancing the peculiar, extraordinary forms of landscapes generated by each typical local product. In Italy, the beautiful rural landscapes built by rural wisdom have allowed our agri-food sector to establish itself on a global scale; "Italian cuisine", the "Mediterranean diet" and "typical regional products" have conquered the international market for the variety and quality of the offer. The "fairy tale landscapes", which attract tourists from all over the world, have also become "table landscapes", that is, concrete certificates guaranteeing quality products and protecting the commercial income of local communities; we risk losing them if we want to replicate them to answer the planetary demand of the urban population. 


\section{Conclusions}

What we have argued so far leads to the conclusion that the agricultural world can and should be seen as a potential pool of innovative offers, useful for building new social relations and for creating a new economy that is slower, less aggressive and ultimately, fairer and more sustainable. The eloquent example of the agri-food sector is sufficient to demonstrate why and how the countryside can teach urban society what rhythms of life and how consumption is today more convenient and appropriate.

It is time to overturn the balance of power that subjected agricultural spaces to the commercial demand of the city; it is necessary to move from product landscapes (arable land, specialized arboriculture, rice fields) to landscape products (Sabina oil, Casentino ham, Colli Lanusini wine) and strongly reaffirm that quality assurance in agri-food coincides with the protection of agricultural areas and their landscapes. It is nice to observe that in this post-globalist and post-productive perspective, even micro and small agricultural companies, the most committed to meeting the needs of a niche market (typical, organic, artisan products), will be able to reaffirm their economic functionality. - social and territorial.

Author Contributions: M.G. 1. Introduction, 2. Method and material, 4. Discussion, 5 Conclusions. P.F. 3. Results Conflicts of Interest: The authors declare no conflict of interest. 


\section{References}

1. Atkins, P.; Bowler, I. Food in Society. Economy, Culture, Geography; Hodder Education: London, United Kingdom, 2001.

2. UN-Habitat. Urban-Rural Linkages: Guiding Principles. Framework for Action to Advance Integrated Territorial Development; 2019. Available online: https://unhabitat.org/sites/default/files/2020/03/url-gp-1.pdf (accessed on $10 / 01 / 2021)$.

3. FAO. The State of Food and Agriculture Leveraging Food Systems for Inclusive Rural Transformation, 2017. Available online: http://www.fao.org/3/a-i7658e.pdf (accessed on 10/01/2021)

4. GIZ; FAO; RUAF. City Region Food Systems and Food Waste Management Linking Urban and Rural Areas for Sustainable and Resilient Development, 2016. Available online: http://www.fao.org/3/a-i6233e.pdf, (accessed on 10/01/202)

5. Ministero delle politiche agricole alimentari e forestali. Carta di Milano, Available online: https://www.politicheagricole.it/flex/cm/pages/ServeBLOB.php/L/IT/IDPagina/9341 (accessed on 10/01/2021)

6. Dansero, E.; Marino, D.; Mazzocchi, G.; Nicolarea, Y., Eds. Lo spazio delle politiche locali del cibo: temi, esperienze e prospettive; Atlante del cibo, Italy, 2019.

7. Sonnino, R. The new geography of food security: exploring the potential of urban food strategies. The Geographical Journal 2016, 182, pp. 190-200.

8. Sonnino, R.; Spayde, J. The New Frontier? Urban strategies for food security and sustainability. In Sustainable Food Systems: Building a New Paradigm; Marsden, T.; Morley, A., Eds.; Earthscan: London, United Kingdom, 2014, pp. 186-205.

9. Montanari, M.; Sabban, F., eds. Storia e geografia dell'alimentazione; Utet: Torino, Italy, 2006.

10. Boccaccio, G. Decameron; Fabbri editore: Bergamo, Italy: 1995.

11. Feagan, R. The place of food: mapping out the 'local' in local food systems. Progress in Human Geography 2007, 31, pp. 23-42.

12. Goodman, M. Food geographies I Relational foodscapes and the busy-ness of being more-than-food. Progress in Human Geography 2016, 40, pp. 257-266.

13. Suttie, D.; Hussein, K. Territorial approaches, rural-urban linkages and inclusive rural transformation Ensuring that rural people have a voice in national development in the context of the SDGs; IFAD, 2015, Available online: https://www.ifad.org/documents/38714170/40253256/GER internal_print.pdf/52c96da0ac57-46be-a3cd-86eb445bd471 (accessed on 10/01/2021).

14. Blay-Palmer, A.; Conaré, D.; Meter, K.; Di Battista, A.; Johnston, C., Eds. Sustainable Food System Assessment. Routledge: London, United Kingdom, 2020, https://doi.org/10.4324/9780429439896.

15. Cook, I. Geographies of food: following. Progress in Human Geography 2006, 30, pp. 655-666.

16. Cook, I. Geographies of food: Mixing. Progress in Human Geography 2008, 32, pp. 821-833.

17. Cook, I. et al. Geographies of food: 'Afters'. Progress in Human Geography 2011, 35, pp. 104-120.

18. FAO; RUAF. A vision for City Region Food Systems, Rome, Italy, Available online: http://www.fao.org/3/ai4789e.pdf (accessed on 10/01/2021).

19. Grewal, S. S.; Grewal, P. S. Can cities become self-reliant in food? Cities 2012, 29, pp. 1-11, https://doi.org/10.1016/j.cities.2011.06.003.

20. Orsini, F.; Gasperi, D.; Marchetti, L. et al. Exploring the production capacity of rooftop gardens (RTGs) in urban agriculture: the potential impact on food and nutrition security, biodiversity and other ecosystem services in the city of Bologna. Food Sec. 2014, 6, pp. 781-792, https://doi.org/10.1007/s12571-014-0389-6

21. Grillotti Di Giacomo, M. G.; De Felice, P. L'agroalimentare italiano tra globale e locale: le abitudini alimentari prima e durante la pandemia virus COVID-19, Documenti geografici 2020, 1, p. 245-259, doi:http://dx.doi.org/10.19246/OCUGEO2281-7549/202001_15.

22. Cattivelli, V.; Rusciano, V. Social innovation and food provisioning during Covid-19: The case of urbanrural initiatives in the Province of Naples, Sustainability 2020, 12(11), 4444, https://doi.org/10.3390/su12114444

23. Global Forum for Food and Agriculture, Communiqué 8 th Berlin Agriculture Ministers' Summit 201616 January 2016. How to feed our cities? - Agriculture and rural areas in an era of urbanization, Available online: https://www.gffa-berlin.de/wp-content/uploads/2015/10/GFFA_Kommunique_2016_EN.pdf (accessed on 10/01/2021). 
24. Grillotti Di Giacomo, M. G. Una geografia per l'agricoltura. Metodologie di analisi e prospettive applicative per il mondo agrario e rurale italiano. Reda: Roma, Italy, 1992.

25. Grillotti Di Giacomo, M. G. Una geografia per l'agricoltura. Lo sviluppo agricolo nello sviluppo territoriale italiano. Società Geografica Italiana: Roma, Italy, 2000.

26. Conti Puorger, A. Caratteri strutturali dell'agricoltura in Francia. In Atti del Convegno Geografico Internazionale I valori dell'agricoltura nel tempo e nello spazio; Grillotti Di Giacomo, M. G., Moretti, L., Eds.; Brigati: Genova, Italy, 1998; pp. 1015-1026.

27. Di Carlo, P. I Caratteri strutturali dell'agricoltura spagnola. In Atti del Convegno Geografico Internazionale I valori dell'agricoltura nel tempo e nello spazio; Grillotti Di Giacomo, M. G., Moretti, L., Eds.; Brigati: Genova, Italy, 1998; pp. 1053-1077.

28. Falcioni, P. I Caratteri strutturali dell'agricoltura nel Regno Unito. In Atti del Convegno Geografico Internazionale I valori dell'agricoltura nel tempo e nello spazio; Grillotti Di Giacomo, M. G., Moretti, L., Eds.; Brigati: Genova, Italy, 1998; pp. 939-969.

29. Moretti, L. Caratteri strutturali ed economici dell'agricoltura in Grecia. In Atti del Convegno Geografico Internazionale I valori dell'agricoltura nel tempo e nello spazio; Grillotti Di Giacomo, M. G., Moretti, L., Eds.; Brigati: Genova, Italy, 1998; pp. 1131-1153.

30. Palumbo, D.; Riggio, A. I caratteri strutturali ed economici dell'agricoltura della Turchia. In Atti del Convegno Geografico Internazionale I valori dell'agricoltura nel tempo e nello spazio; Grillotti Di Giacomo, M. G., Moretti, L., Eds.; Brigati: Genova, Italy, 1998; pp. 1229-1253.

31. Scarpelli, L.; Castagnoli, D. I sistemi agricoli della nuova Repubblica Federale di Germania. In Atti del Convegno Geografico Internazionale I valori dell'agricoltura nel tempo e nello spazio; Grillotti Di Giacomo, M. G., Moretti, L., Eds.; Brigati: Genova, Italy, 1998; pp. 971-994.

32. Grillotti Di Giacomo, M. G. The Italian Rural Systems Atlas, Brigati, Genova, Italy, 2005.

33. Morelli, P. Umbria, Reda: Roma, Italy, 1993.

34. Moretti, L. Molise, Reda: Roma, Italy, 1993.

35. Scarpelli, L. Friuli-Venezia Giulia, Reda: Roma, Italy, 1993.

36. Di Carlo, P., Marche, Reda: Roma, Italy, 1993.

37. Trischitta, D., Calabria, Reda: Roma, Italy, 1993.

38. Grosso, N.; Rollando, A.; Spotorno, M. Liguria, Reda: Roma, Italy, 1994.

39. Massimi, G. Abruzzo, Reda: Roma, Italy, 1994.

40. Moretti, L. Campania, Reda: Roma, Italy, 1995.

41. Falcioni, P. Toscana, Reda: Roma, Italy, 1995.

42. Scarpelli, L. Veneto, Reda: Roma, Italy, 1996.

43. Loi, A.; Zaccagnini, M. Sardegna, Reda: Roma, Italy, 1996.

44. Di Carlo, P. Puglia, Reda: Roma, Italy, 1996.

45. Morelli, P. Basilicata, Reda: Roma, Italy, 1996.

46. Moretti, L. Lazio, Società Geografica Italiana, Roma, Italy, 1999.

47. Truffelli, C. Emilia Romagna, Società Geografica Italiana, Roma, Italy, 2000.

48. Grillotti Di Giacomo, M.G. Nutrire l'uomo, vestire il Pianeta Alimentazione-Agricoltura-Ambiente tra imperialismo e cosmopolitismo. Franco Angeli: Milano, Italy, 2018.

49. Kostrowicki, J. Geografia dell'agricoltura. Ambienti, società, sistemi, politiche dell'agricoltura, FrancoAngeli: Milano, Italy, 1983.

50. Kay, S. et al. Extent of Farmland Grabbing in the Eu Study, European Union: Brussels, Kingdom of Belgium, 2015, Available online: http://www.europarl.europa.eu/studies (accessed on 10/01/2021).

51. Kay, S. Landgrabbin and landconcentration in Europe. A research brief, Transnational Institute for HOTL: Amsterdam, Netherlands, 2016.

52. Franco, J.; Borras Jr. M. S., Eds. Land concentration, land grabbing and peoples struggles in Europe, Transnational Institute (TNI) for European Coordination Via Campesina and Hands off the Land network, 2013, Available online: https://www.tni.org/files/download/land in europe-jun2013.pdf (accessed on 10/01/2021).

53. Bouniol, J. Scramble for land in Romania: an iron fist in a velvet glove. In Land concentration, land grabbing and peoples struggles in Europe Franco, J., Borras Jr. M. S., Eds.; Transnational Institute (TNI) for European Coordination Via Campesina and Hands off the Land network, 2013, Available online: https://www.tni.org/files/download/land_in_europe-jun2013.pdf (accessed on 10/01/2021). 
54. Grillotti Di Giacomo, M. G., Atlante tematico dell'agricoltura italiana, Società Geografica Italiana: Roma, Italy, 2000.

55. Grillotti Di Giacomo, M. G., De Felice, P., I predatori della terra. Land Grabbing e Land Concentration tra neocolonialismo e crisi migratory. Franco Angeli: Milano, Italy, 2019.

56. Dansero, E.; Pettenati, G.; Toldo A. Il rapporto fra cibo e città e le politiche urbane del cibo: uno spazio per la geografia? Bollettino della Società Geografica Italiana 2017, XIII, X, pp. 5-22.

57. Pettenati, G.; Toldo, A. Il cibo tra azione locale e sistemi globali. Spunti per una Geografia dello sviluppo, Franco Angeli: Milano, Italy, 2018.

58. Thebo, A. L.; Drechsel, P.; Lambin E. F. Global assessment of urban and peri-urban agriculture: irrigated and rainfed croplands. Environmental Research Letters, 2014, 9, 11402, Available online: http://iopscience.iop.org/1748-9326/9/11/114002/article (accessed on 10/01/2021).

59. Pothukuchi, K. E.; Kaufman, J. The food system: A stranger to the planning field, Journal of the American Planning Association, 2000, 66, pp. 113-124.

60. Dupuis, E.M.; Goodman D. Should we go "home" to eat?: toward a reflexive politics of localism, Journal of Rural Studies, 2005, 21, 3, pp. 359-371. 